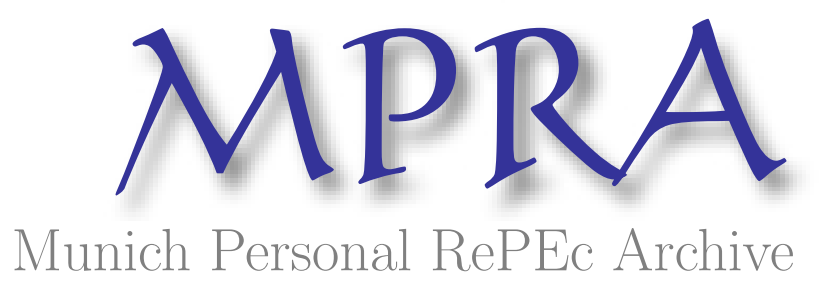

\title{
On the stability of the Ramsey accumulation path
}

Bellino, Enrico

28. January 2013

Online at http://mpra.ub.uni-muenchen.de/44024/ MPRA Paper No. 44024, posted 28. January 2013 / 09:43 


\title{
On the stability of the Ramsey accumulation path
}

\author{
Enrico Bellino ${ }^{2}$
}

December $4^{\text {th }}, 2012$ - forthcoming in Levrero S., Palumbo A. and Stirati A. (eds.), Sraffa and the Reconstruction of Economic Theory, Vol. 1, Theories of Value and Distribution, Palgrave Macmillan, Houndmills, Basingstoke, Hampshire, UK, 2013.

\begin{abstract}
The Ramsey (1928) accumulation path is characterized as a saddle-path in the standard presentations of the model based on the works of Cass (1965) and Koopmans (1965). From a mathematical stance a saddle-path is unstable: if the system is exactly on that path, it converges to the steady state of the system; if it diverges slightly from that path, it shifts indefinitely from the steady state. The 'transversality' condition is then invoked in the Ramsey model to prevent the system from following such divergent paths; from the economical point of view this condition can be interpreted as a perfect foresight assumption. This kind of instability, which is typical of infinite horizon optimal growth models, has been sometime considered to account for actual economic crises. The claim would seem to be grounded on the idea that if the consumer optimizes myopically, i.e., by only considering the current and the subsequent period, the ensuing dynamics diverges almost surely from the steady state equilibrium. Convergence requires perfect foresight.

The present work aims to challenge this conclusion, which seems not inherent to the choice problem between consumption and savings, but it is due to the presumption the consumer must face this problem in an infinite horizon setting. The Ramsey problem of selection of the accumulation path will be re-proposed here within a framework where consumer's ability to optimize over the future is assumed to be imperfect. However, the ensuing path will converge to the steady state, without assuming perfect foresight. Myopia is thus not ultimately responsible for the instabilities of the 'optimal' accumulation path. Explanations of instability phenomena of actual economic systems (crises, bubbles, etc.) must be sought in other directions, probably outside the strait-jacket of the optimization under constraint.
\end{abstract}

\section{Introduction}

Infinite horizon Neoclassical optimal accumulation theory is characterized by an analytical apparatus that has now pervaded several fields of theoretical analysis: capital theory, growth and value theory, macrodynamics, ecc. In this context the equilibrium solutions take the form of saddle-paths which are, therefore, unstable paths. The convergence of these solutions to the steady state equilibrium is then ensured by imposing a transversality condition, that is, a condition which guarantees the optimality of the solution when time tends to infinity.

\footnotetext{
${ }^{1}$ The material presented in this paper is fruit of a set of discussions stimulated by Pierangelo Garegnani on the meaning of the 'transversality condition' within optimal capital accumulation models. I am sincerely grateful for having had these discussions with him. In addition, I wish to thank Andrea Battinelli, Carlo Beretta, Marco Bramanti, Thomas Christiaans, Roberto Ciccone, Ferdinando Colombo, Saverio Fratini, Kazuhiro Kurose, Enrico Sergio Levrero, PierCarlo Nicola, Fabio Petri, Mario Pomini, Neri Salvadori, Paolo Trabucchi, Alessandro Sbuelz, Gerd Weinrich and an anonymous referee for their comments and suggestions on earlier versions of this work. However, the responsibility of what is written here is entirely mine. Finally, I am grateful to Micaela Tavasani, for English revision.

2 Università Cattolica del Sacro Cuore, Largo Gemelli 1, 20123 - Milano, Italy; e-mail: enrico.bellino@unicatt.it.
} 
Sometimes, this kind of dynamics has been considered to account for the crises of actual economic systems. A quite recent work supporting this position is proposed by Christopher Bliss:

Question: Which Cambridge, England, paper of the 1960s or 1970s did more damage to simple neoclassical thinking than any other? I can imagine the post-Keynesians proposing one or more papers by Joan Robinson, but I would not agree. My own candidate would be Frank Hahn's 1968 paper on warranted growth paths. What Hahn did can be explained quite simply. [...] In general, equilibrium conditions for the various capital goods - that is, equal net returns for each good-depend upon the rate of change of prices, not just on the prices alone. Then the intertemporal dynamic equilibrium of the system is defined by a set of simultaneous differential equations. What can we say about those equations? The easiest route to the answer comes from the theory of optimal growth, as with a many-capital-good Ramsey model. From there we obtain dynamic equilibrium conditions (Euler equations), but these do not suffice by themselves. We need to add transversality conditions. The dynamic equations are of the saddle-point variety. Only transversality ensures that the system converges to the right asymptotic state. Hahn, following a suggestion from Mirrlees, realized that a non-optimized dynamic equilibrium is just like the necessary conditions for an optimized system. There will be infinitely many 'equilibrium' paths for prices, but most of these will crash into the sign-constraint barriers of the race track.

In other words, a successful capitalist economy needs to have the right idea of where it should go in the long run. It would be hard to imagine a more telling criticism of the theoretical claim that an ideal decentralized capitalist system exhibits optimal properties. For if there is one thing that capitalist economies are really bad at, it is knowing where they are going in the long run and judging that destination correctly. Recent financial crises, and similar crises in the past, remind us that capitalism is like an inexperienced child that chases after the latest shiny attraction until it hurts itself and ends up in tears (Bliss, 2010, pp. 648-9).

This quotation hints at several related issues, sometime mixed up; roughly, Bliss seems to suggest that Neoclassical optimal accumulation models aim to account for both the equilibrating and the destabilizing forces of capitalist economies. He seems to say that crises in actual capitalist economies can be explained, at least partially, by the destabilizing forces implicit in Neoclassical optimal growth theory. At a deeper level, this claim would seem to be grounded on the idea that if the consumer optimizes myopically, i.e., by considering only the current and the subsequent period, the ensuing dynamics diverges almost surely from the steady state equilibrium. On the contrary, convergence to the steady state equilibrium requires consumer's perfect foresight. Myopic optimization, in other words, would be actually the 'responsible' for the instabilities, while long-run foresight is the assumption that guarantees the convergence of short run or momentary equilibria towards a steady state. An interesting analysis of the role of consumer foresight ability in connection with the dynamic properties of the optimal accumulation path is proposed by Heller ${ }^{3}$ :

It is a curious fact that while most finite time horizon economic models are stable, almost all infinite time horizon models are unstable. ... Hahn [Q.J.E., 1966 and R.E.S., 1968, e.b.] and Shell-Stiglitz [Q.J.E., 1967 , e.b.] cast considerable doubt for simple 'descriptive' economic models that efficient equilibrium paths are ever chosen by myopically optimizing, competitive agents when there is no end to time. In Ramsey planning models, there is a similar instability: if central planners initially choose the right path, minor external shocks could cause them to follow a non-optimal path when they operate according to

\footnotetext{
${ }^{3}$ This work was pointed out to me by Fabio Petri.
} 
myopic optimization rules ... It may be helpful to spell out this point a bit further. The infinite horizon models of Hahn and others restrict attention to momentary equilibrium paths arising from arbitragers possessing self-fulfilling expectations about price changes in the immediate future (we will call this myopic foresight). A path is in equilibrium at a moment in time if, given current prices and myopic foresight expectations about prices in the immediate future, agents make plans about the allocation of resources across consumption and various investment goods that clear markets at the current moment. Paths that are in equilibrium for non-infinitesimal lengths of time, but are not necessarily in equilibrium for all time, are called momentary equilibrium paths. Paths that are in equilibrium at every moment in time are called long run equilibrium paths. Momentary equilibrium paths need not be long run equilibrium paths because, for example, the stock of some capital good is run down to zero at some point, resulting in a disequilibrium at that time (Heller, 1975, pp. 65-6).

In these pages I aim to challenge the idea that myopic optimization is ultimately responsible for instability and that the assumption of perfect foresight is the only way to avoid it. In this work we will limit our investigation to an optimal accumulation model with just one good, in order to focus on the causes of instability in the simplest situation in which it emerges. We will study a myopic adjustment process compatible with consumer rational behaviour; the ensuing accumulation path will be proved to converge monotonically to the Ramsey steady state equilibrium. The extension to the cases with more than one good, which are those considered by Hahn and referred to by Bliss, will be undertaken in a subsequent work.

\section{Setting of the Cass-Koopmans-Ramsey model}

Let us consider what the (representative) consumer has to do in order to discover his optimal consumption path over an infinite time horizon. Consider an economic system where just one commodity is produced, consumed and employed jointly with labour as a mean of production of itself; capital depreciates at rate $\mu \in[0,1]$. We define period $t$ the half-open time interval $[t, t+1)$ between dates $t$ and $t+1$. Consumers live forever, and they are all equal. We can thus study the behaviour of the representative consumer. To simplify, let us suppose that population remains constant. Time is considered a discrete variable, making it easier to analyse the situation as a sequence of events ${ }^{4}$. Consumer's preferences have a cardinal representation, ${ }^{5}$ being described by an utility functional, $U=\sum_{t=0}^{+\infty}\left(\frac{1}{1+\theta}\right)^{t} u\left(c_{t}\right)$, constituted by a sum of discounted utilities achieved in each period, $u\left(c_{t}\right)$, where $c_{t}$ is the consumption level in period $t,{ }^{6} \frac{1}{1+\theta}$ is the discount factor of future utility and $\theta>0$ is the rate of time preference. We suppose that $u: \mathbf{R}^{+} \rightarrow \mathbf{R}$ is a twice continuously differentiable, increasing and concave function; hence $u^{\prime}\left(c_{t}\right)>0$ and $u^{\prime \prime}\left(c_{t}\right)<0$; by simplicity, let's assume also $\lim _{c_{t} \rightarrow 0^{+}} u^{\prime}\left(c_{t}\right)=+\infty$.

Technology is described by the per-capita production function, $f\left(k_{t}\right)$, where $f\left(k_{t}\right)$ is the flow of per worker gross output (gross of capital replacements) and $k_{t}$ is the per worker flow of

\footnotetext{
${ }^{4}$ For discrete time versions of the Ramsey model see, for example, Azariadis (1993, Chaps. 7 and 13) or Stockey and Lucas (1989, Chap. 2).

${ }^{5}$ See Koopmans (1965, Section I); see also Hicks (1965, Chap. XXI, in particular pp. 256-7 and Appendix E).

${ }^{6}$ In this discrete time setting 'period $t$ ' means the time interval that starts at instant $t$ and ends at instant $t+1$.
} 
services from the real capital stock. $f: \mathbf{R}^{+} \rightarrow \mathbf{R}^{+}$is a twice continuously differentiable, increasing and concave function; hence $f^{\prime}(k)>0$ and $f^{\prime \prime}(k)<0$. Moreover, $f(0)=0$, $\lim _{k \rightarrow 0^{+}} f^{\prime}(k)=+\infty$ and $\lim _{k \rightarrow+\infty} f^{\prime}(k)=0^{+}$.

Now, let's analyse the 'centralized' solution, i.e., the consumption path maximizing consumer utility over the whole period considered:

$$
\max _{\left\{c_{t}, k_{t}\right\}} U=\sum_{t=0}^{+\infty}\left(\frac{1}{1+\theta}\right)^{t} u\left(c_{t}\right)
$$

where

$$
c_{t}=f\left(k_{t}\right)-\mu k_{t}-\left(k_{t+1}-k_{t}\right), \quad t=0,1,2, \ldots
$$

and

$$
k_{0}=\bar{k}_{0}
$$

where $\bar{k}_{0}$ is the (given) initial capital endowment per worker.

As regards the meaning of the physical constraint $(\mathrm{Ct}) k_{t}$ observe that, without loss of generality, we can assume that each unit of capital provides a unitary flow of capital service within the period, so that the same symbol $k_{t}$ denotes the per worker flow of services from the real capital stock (when it appears as argument of function $f$ ) and the per-worker capital stock available at date $t$, that is, at the beginning of period $t$. On the other hand, $f\left(k_{t}\right)-\mu k_{t}$ and $c_{t}$ are the flows of net product per worker and of consumption per worker during period $t$ ('yearly' flows). Suppose that within each period a uniform flow of net output and of consumption is made available by the production process (a 'daily' flow); in this way the contemporaneity between production and consumption entailed in $(\mathrm{Ct})$ does not raise problems from the logical point of view. ${ }^{7}$ Moreover, suppose that the new capital accumulated during period $t$ starts to generate capital services only with the beginning of the subsequent period ('time do build' assumption); in this way we can disregard the formation of new capital during the period.

Let's suppose that $\bar{k}_{0}<\tilde{k}$, where $\tilde{k}$ is that level of capital labour ratio which makes the net product per worker equal to zero, i.e.

$$
f(\tilde{k})=\mu \tilde{k} .
$$

\footnotetext{
${ }^{7}$ Alternatively we could express the physical constraint in the form

$$
c_{t+1}=f\left(k_{t}\right)-\mu k_{t}-\left(k_{t+1}-k_{t}\right), t=0,1,2, \ldots ;
$$

in this way consumption, as well as net investment, takes place at the end of the production period. The formulation $\left(\mathrm{Ct}^{\prime}\right)$ of the physical constraint is however uncommon in the literature; exceptions are Malinvaud (1965, pp. 311-2, in particular formulas (4) and (7)), or Mas-Colell, Whinston and Green (1995, pp. 747, item (iii)), or Nicola (2000, p. 352, formula (24.3)). Anyway, the use of constraint $\left(\mathrm{Ct}^{\prime}\right)$ does not alter results in a significant manner. We will return later on this point.
} 
The optimal path of consumption ${ }^{8} c_{t}$, with $t=0,1,2,3, \ldots$ and of capital, $k_{t}$, with $t=1$, $2,3, \ldots$ can be found as follows: ${ }^{9}$ at the beginning of each period $t$ the stock of capital, $k_{t}$, is determined by past saving decisions. After substituting the physical constraints $(\mathrm{Ct})$ in the utility functional, there are just two addenda that include $k_{t+1}$ :

$$
\begin{aligned}
& U=\sum_{\tau=0}^{+\infty}\left(\frac{1}{1+\theta}\right)^{\tau} u\left[f\left(k_{\tau}\right)-\mu k_{\tau}+k_{\tau}-k_{\tau+1}\right]= \\
& \cdots+\frac{u\left[f\left(k_{t}\right)-\mu k_{t}+k_{t}-k_{t+1}\right]}{(1+\theta)^{t}}+\frac{u\left[f\left(k_{t+1}\right)-\mu k_{t+1}+k_{t+1}-k_{t+2}\right]}{(1+\theta)^{t+1}}+\cdots
\end{aligned}
$$

Derive $U$ with respect to $k_{t+1}$ and set the result equal to zero; after simplifying we have:

$$
u\left[f\left(k_{t}\right)-\mu k_{t}+k_{t}-k_{t+1}\right]=u\left[f\left(k_{t+1}\right)-\mu k_{t+1}+k_{t+1}-k_{t+2}\right] \frac{f^{\prime}\left(k_{t+1}\right)-\mu+1}{\theta+1}, \quad t=0,1,2, \ldots ;
$$

and re-substituting $(\mathrm{Ct})$ and $(\mathrm{Ct}+1)$ we obtain: ${ }^{10}$

$$
u^{\prime}\left(c_{t}\right)=\frac{u^{\prime}\left(c_{t+1}\right) \cdot\left[1-\mu+f^{\prime}\left(k_{t+1}\right)\right]}{1+\theta}, \quad t=0,1,2, \ldots
$$

To understand the economic meaning of conditions (UCt), consider the consumption allocation problem faced by the representative consumer between periods $t$ and $t+1$. If the consumer decreases consumption in period $t$ by $\mathrm{d} c_{t}$, the ensuing loss of utility is $u^{\prime}\left(c_{t}\right) \mathrm{d} c_{t}$. This decrease in consumption of period $t$ allows for more accumulation: gross output of period $t+1$ increases by $f^{\prime}\left(k_{t+1}\right) \mathrm{d} c_{t}$. Consumption of period $t+1$ may be increased by $\left[f^{\prime}\left(k_{t+1}\right)-\right.$ $\mu+1] \mathrm{d} c_{t}$, including what is left of the initial amount of capital invested. This will increase utility of period $t+1$ by $u^{\prime}\left(c_{t+1}\right)\left[f^{\prime}\left(k_{t+1}\right)-\mu+1\right] \mathrm{d} c_{t}$. Along the optimal path these (small) reallocations of consumption must leave welfare unchanged: the loss in utility of period $t$ must compensate the discounted increase of utility of period $t+1$, that is:

$$
u^{\prime}\left(c_{t}\right) \mathrm{d} c_{t}=\frac{u^{\prime}\left(c_{t+1}\right)\left[f^{\prime}\left(k_{t+1}\right)-\mu+1\right] \mathrm{d} c_{t}}{1+\theta} .
$$

\footnotetext{
${ }^{8}$ Throughout the work consumption is intended as consumption 'per worker'; the same can be said for net product, saving and capital. For the sake of brevity, we will omit this specification.

${ }^{9}$ Here we follow closely Azariadis (1993, $§ 7.3$ and $\S 13.4$ ); for the more usual continuous time case see Blanchard and Fischer $(1989, \S 2.1)$.

${ }^{10}$ A similar condition can be obtained for the continuous case; see, for example, Blanchard and Fischer $(1989, \S$ 2.1). By writing the physical constraint in the form $\left(\mathrm{Ct}^{\prime}\right)$, conditions $(\mathrm{U} t)$ would remain unaltered, with the only difference that now the arguments of the marginal utilities at the left-hand and at the right-hand are now $c_{t+1}$ and $c_{t+2}$; consequently conditions ( $\mathrm{UC} t$ ) take the form
}

$$
u^{\prime}\left(c_{t+1}\right)=\frac{u^{\prime}\left(c_{t+2}\right) \cdot\left[1-\mu+f^{\prime}\left(k_{t+1}\right)\right]}{1+\theta}, \quad t=0,1,2, \ldots
$$


After simplification we obtain equations (UCt). The left-hand and the right-hand members of (UCt) could be called 'marginal utility of consumption' and 'marginal utility of savings'. It is to be noted that the optimization process entailed by condition (UCt) concerns just two periods at a time: $t$ and $t+1$. The integral consumption of what remains of the additional capital transferred from period $t$ to $t+1$ sterilizes any effect of this capital accumulation for periods $t+2, t+3$, ecc. This allows us to focus just on costs and benefits for periods $t$ and $t+1$. No costs and benefits due to reallocations between periods $t$ and $t+1$ arise for $t+2, t+$ $3, \ldots$; otherwise these effects should have been taken into account in identifying the optimal intertemporal allocation.

Physical constraints ( $\mathrm{Ct}$ ) and the 'equi-marginality' equalities (UCt) are necessary conditions to select the optimal behaviour of the representative consumer. The steady-state of the system (UCt)-(Ct) is represented by the pair $\left(k^{*}, c^{*}\right)$, where $k^{*}$ is that value of $k$ such that

$$
f^{\prime}\left(k^{*}\right)=\theta+\mu
$$

and $c^{*}=f\left(k^{*}\right)-\mu k^{*}$. Equation (2) is called the 'modified golden rule', as it differs from the traditional 'golden rule',

$$
f^{\prime}\left(k_{g}\right)=\mu \text {, }
$$

which is the condition to select the capital labour ratio, $k_{g}$, that maximizes the net product per worker, $f(k)-\mu k$. As $f^{\prime}$ is decreasing we have

$$
k^{*}<k_{g}<\tilde{k} .
$$

For further reference, it is useful to represent on two graphs the curve of net product and its derivative (see Figure 1). 


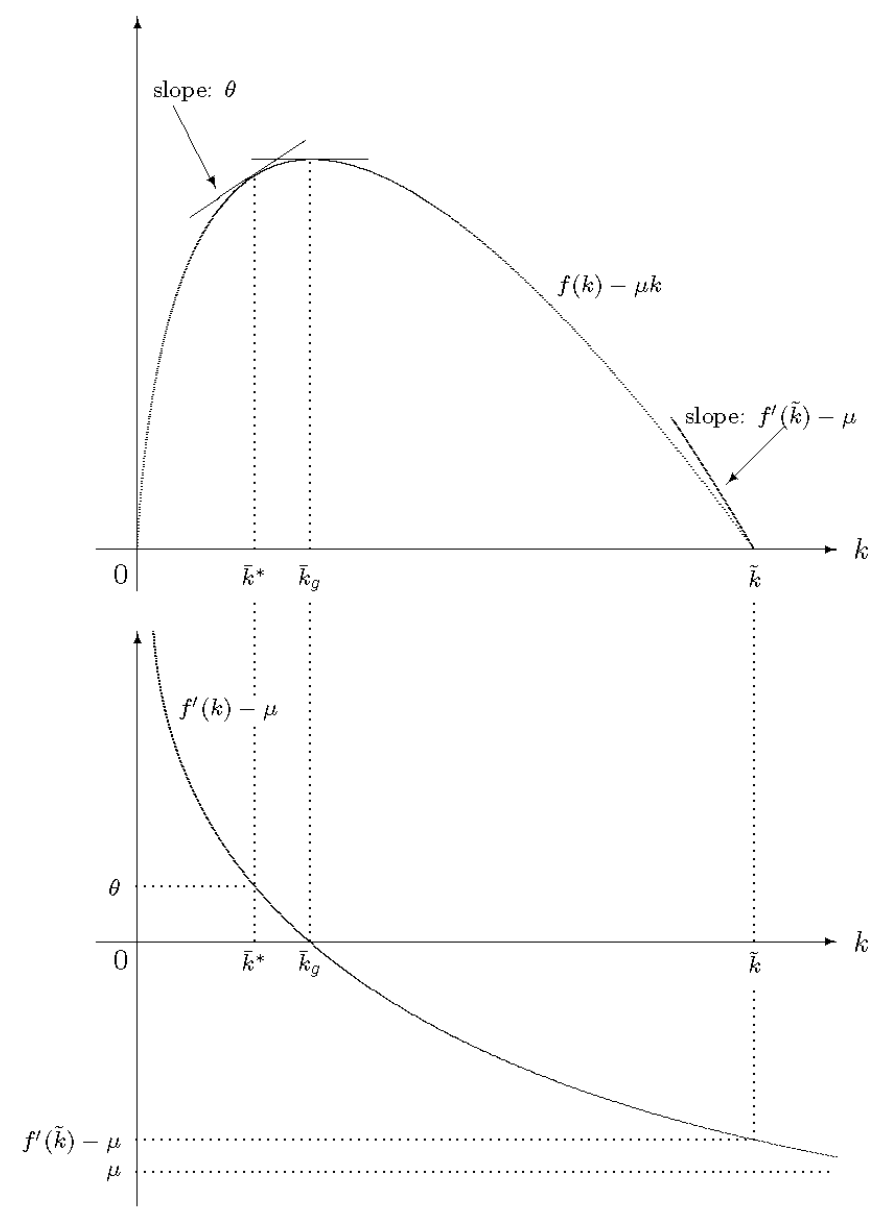

Figure 1. Net product, $f(k)-\mu k$, and its derivative, $f^{\prime}(k)-\mu$

\section{Excluding divergent paths: the transversality condition}

The dynamics described by equations ( $\mathrm{UCt}$ ) and $(\mathrm{Ct})$ can be analysed by the phase portrait represented in Figure 2. The curves $f(k)-\mu k$ and $k=k^{*}$ divide the positive quadrant in four regions: 1, 2, 3 and 4 . The direction of the movement in each of these regions is described by the small arrows: by $(\mathrm{Ct})$ we deduce that $k_{t+1} \gtrless k_{t}$ if and only if $c_{t} \lesseqgtr f\left(k_{t}\right)-\mu k_{t}$; by (UCt) we deduce that $c_{t+1} \gtrless c_{t}$ if and only if $k_{t} \lessgtr k^{*}$. The direction of arrows suggest that the dynamics of $k_{t}$ and $c_{t}$ is a saddle path, that is, an unstable path. The cause of this instability lies in the peculiar way in which the initial consumption level, $c_{0}$, is selected. Let us focus on this procedure, step by step. At date $t=0$ equations (U) and (C) become

$$
u^{\prime}\left(c_{0}\right)=u^{\prime}\left(c_{1}\right) \frac{1-\mu+f^{\prime}\left(k_{1}\right)}{1+\theta}
$$




$$
\begin{aligned}
& c_{0}=f\left(\bar{k}_{0}\right)-\mu \bar{k}_{0}-\left(k_{1}-\bar{k}_{0}\right) \\
& c_{1}=f\left(k_{1}\right)-\mu k_{1}-\left(k_{2}-k_{1}\right)
\end{aligned}
$$

We have thus three equations in four unknowns: $c_{0}, k_{1}, c_{1}$ and $k_{2}$; one of them must be fixed from outside. In infinite horizon models $c_{0}$ is initially chosen arbitrarily and then one looks if this choice is compatible with utility maximization in the long run. Suppose that $\bar{k}_{0}<k^{*}$; hence $\left[1-\mu+f^{\prime}\left(\bar{k}_{0}\right)\right] /(1+\theta)>1$. If $c_{0}$ is initially fixed at a high level, not too far from the net product $f\left(\bar{k}_{0}\right)-\mu \bar{k}_{0}$ (like, for example, $c_{0}^{\prime}$ in Figure 2), the first member of (U0) will be quite low (since $u^{\prime}$ is decreasing); on the other hand (C0) determines $k_{1}$ not too far from $\bar{k}_{0}$ and thus the ratio $\left[1-\mu+f^{\prime}\left(k_{1}\right)\right] /(1+\theta)$ will remain close to $\left[1-\mu+f^{\prime}\left(\bar{k}_{0}\right)\right] /(1+\theta)$, and thus higher than 1 . Hence, in order to align the r.h.s. of (U0) with the low level reached by $u^{\prime}\left(c_{0}^{\prime}\right)$, future consumption must be fixed at a level higher than $c_{1}^{\prime}$, i.e., $c_{1}^{\prime}>c_{0}^{\prime}$. In other words, given a high initial consumption level, to 'justify' (rationalize) this choice future consumption must be fixed at an even higher level. Analogous adjustments, all entailing an ever increasing consumption in periods $t=2,3, \ldots$ will take place, up to the point where capital is totally devoured! This is what happens along the $S^{\prime} \Sigma^{\prime}$ path of the Cass-Koopmans diagram (see Figure 2): initial consumption is kept fixed at $c_{0}^{\prime}$ and $c_{t}$ is increased (savings are decreased) in all subsequent periods; from point $Z^{\prime}$ on, besides consuming the entire net product of each period, the individual starts 'eating' away the capital stock, until it is dragged to 0 .

If, on the other hand, initial consumption is fixed at a low level, like $c_{0}^{\prime \prime}$ in Figure 2, then $u^{\prime}\left(c_{0}^{\prime \prime}\right)$ will be quite high and (C0) will determine $k_{1}$ at a level which is significantly higher than $\bar{k}_{0}$, so that the ratio $\left[1-\mu+f^{\prime}\left(k_{1}\right)\right] /(1+\theta)$ will be significantly lower than $[1-\mu+$ $\left.f^{\prime}\left(\bar{k}_{0}\right)\right] /(1+\theta)$. In order to keep the r.h.s. of (U0) at the high level of $u^{\prime}\left(c_{0}^{\prime \prime}\right)$ future consumption cannot be fixed at a very high level, in spite of the large accumulation that has just taken place. This leaves a large amount of resources for accumulation, pushing the system into an over-accumulation path, like $S^{\prime \prime} \Sigma^{\prime \prime}$ in Figure 2, where consumption starts decreasing from point $Z^{\prime \prime}$ onwards where $k>k^{*}$, thus making the net marginal productivity of capital fall below the factor of time preference. The system is thus dragged to point $(\tilde{k}, 0)$ where the entire gross product $f(\tilde{k})$ is devoted to the maintenance of capital, $\mu \widetilde{k}:$ the initial error, of a too low initial consumption level, is thus corrected by low levels of future consumptions - which decrease even to zero from a certain point onwards!

It can be proved that there is only one level of initial consumption, $c_{0}^{*}$, that places the consumer on his optimal intertemporal path. All other levels of $c_{0}$ lie in an over-consumption path or in an over-accumulation path. 


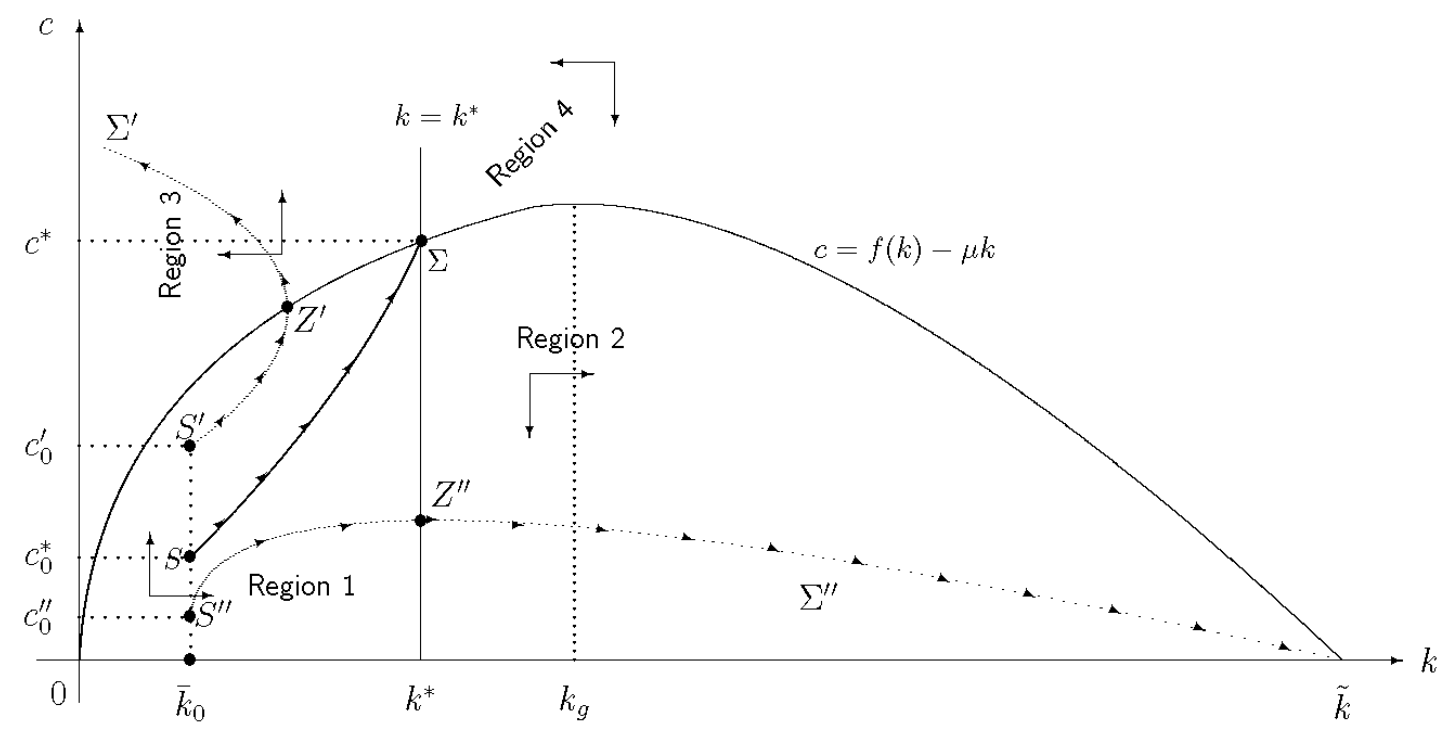

Figure 2. Phase portrait of the Cass-Koopmans-Ramsey model

In both examples, initial consumption is taken as given; this is just a provisional assumption, an analytical device that shows that almost all levels of initial consumption lie on a divergent path: infinitely many divergent paths, like $S^{\prime} \Sigma^{\prime}$, or $S^{\prime \prime} \Sigma^{\prime \prime}$, can be obtained along which the adjustments, necessary for rationalizing the 'error' of fixing an arbitrary level of $c_{0}$, are shifted to future changes, rather than changes in present consumption. These instability phenomena are then amended by introducing a further condition, the so-called 'transversality condition', that excludes all diverging paths like $S^{\prime} \Sigma^{\prime}$ or $S^{\prime \prime} \Sigma^{\prime \prime}$. In formal terms it is represented by

$$
\lim _{t \rightarrow \infty} k_{t} u^{\prime}\left(c_{t}\right)\left(\frac{1}{1+\theta}\right)^{t}=0 .
$$

In all divergent paths $c_{t}$ would become 0 , sooner or later, hence $u^{\prime}(c)$ tends to infinite. This eventuality is excluded by condition $(\mathrm{T})$. But, even if formally correct, this procedure seems to miss the economic substance of the problem. Why should a consumer who wants to optimize his consumption plan commit himself to keeping $c_{0}$ fixed? In his utility maximization problem $c_{0}$ is surely the first variable he will adjust. Obviously, it is not the only variable to consider; rather, he must adjust the whole stream of future consumptions, i.e., infinitely many consumption levels ( $c_{0}$ included)! But while this problem is handy in the finite horizon case $^{11}$, at least in principle, it seems quite difficult or even unsolvable in the

\footnotetext{
${ }^{11}$ With a finite horizon, the solution can be found by fixing a terminal condition, for example, the stock of capital to be left at the end of the periods. Thus, the relevant equations of a three period optimization problem, $[0,1),[1,2)$ and $[2,3)$, are:
} 
infinite horizon case. The selection of the saddle path entails, from the logical point of view, the solution of infinitely many optimization problems: for any given $c_{0}$ the whole path of pairs $\left(k_{t}, c_{t}\right)$ satisfying conditions (UCt) and $(\mathrm{Ct})$ should be calculated; when we realize that it diverges from the steady state - and this will be the case for all but one path-we have to calculate another path starting from another level of $c_{0}$. In this way we would select the unique path converging to the steady state. But this would require almost unlimited computational power for the consumer concerning present and future consumptions and savings. In other terms, it requires long-run or perfect foresight.

Moreover, this way of selecting the optimal path introduces an instability phenomenon which is not inherent to the optimization problem we are studying. It is due both to the presumption that the consumer must face an infinite horizon optimization problem and to the analytical tools available to solve such problem. The crucial difficulty consists in the fact that a rational choice of $c_{0}$ would require at the same time choosing the whole future path $c_{t}, t=1$, $2,3, \ldots$. As this problem is not directly solvable we must resort to the indirect way to fix arbitrarily $c_{0}$ and check later on if the ensuing path converges or diverges. The extraordinary high computational power so required to the consumer makes the model extremely unrealistic. Moreover, it conveys the wrong idea of a structural instability of the long run accumulation path, only remediable by assuming consumer perfect foresight.

In what follows, an alternative way of selecting the optimal accumulation path is proposed, which requires a considerably reduced foresight ability for the consumer. If we realistically limit to assume that in each period the consumer is able to balance the marginal effects of reallocations over a finite number of periods, we obtain a path convergent to the steady state

$$
\begin{aligned}
& u^{\prime}\left(c_{0}\right)=\frac{u^{\prime}\left(c_{1}\right)\left[1-\mu+f^{\prime}\left(k_{1}\right)\right]}{1+\theta} \\
& u^{\prime}\left(c_{1}\right)=\frac{u^{\prime}\left(c_{2}\right)\left[1-\mu+f^{\prime}\left(k_{2}\right)\right]}{1+\theta} \\
& c_{0}=f\left(\bar{k}_{0}\right)-\mu \bar{k}_{0}-\left(k_{1}-\bar{k}_{0}\right) \\
& c_{1}=f\left(k_{1}\right)-\mu k_{1}-\left(k_{2}-k_{1}\right) \\
& c_{2}=f\left(k_{2}\right)-\mu k_{2}-\left(k_{3}-k_{2}\right)
\end{aligned}
$$

We have 5 equations in 6 unknowns: $c_{0}, c_{1}, c_{2}, k_{1}, k_{2}$, and $k_{3}$. A further equation is required to cap the degree of freedom. One possibility is to impose the total exhaustion of capital at the end of the planning period, i.e.,

$$
k_{3}=0 .
$$

The missing equation is in this case a terminal condition. (Alternatively, any other equation fixing the terminal capital at a given positive level could be adopted to close the system.) In the literature on the subject the transversality condition for the infinite horizon case is often introduced by passing to the limit the terminal condition of the finite horizon case; see, for example, Blanchard and Fischer (1989, p. 43). 
that is optimal within the set of constraints imposed on the consumer's ability to optimize over the future. Obviously, it is necessarily sub-optimal if compared with the saddle path, being the result of a set of optimizations defined over a more restrictive set of constraints but, 'better is the enemy of good', as an Italian proverb states. A set of scenarios can thus be outlined where perfect foresight is no longer necessary to exclude divergent paths: myopic optimizing rules are compatible with the convergence to the steady state.

\section{An alternative approach: adjustments towards the optimal path}

Given

$$
k_{0}=\bar{k}_{0}<k^{*}
$$

one possible choice, that the consumer can adopt, is to consume the entire net product in each period. By $(\mathrm{C} t)$ we see that this choice is feasible and entails

$$
k_{t+1}^{\circ}=k_{t}^{\circ}=\bar{k}_{0} \quad \text { and } \quad c_{t}^{\circ}=f\left(\bar{k}_{0}\right)-\mu \bar{k}_{0} \quad \text { for any } t=0,1,2, \ldots .
$$

This is not a unique option and probably not the optimal one. It is a provisional choice ${ }^{12}$ that can be used as a starting point to begin fixing ideas.

In this situation, consider the intertemporal re-allocation constituted by (a) and (b) below:

(a) in period $t=0$ save and invest 1 unit of the good;

(b) the unit saved in period $t=0$ results in

$$
f^{\prime}\left(\overline{k_{0}}\right)-\mu
$$

units of additional net product in all future periods $t=1,2,3, \ldots$.

The effects of (a) and (b) on consumer's welfare are:

(A) a loss of utility for saving 1 unit in period $t=0$ given by ${ }^{13}$

$$
u^{\prime}\left[f\left(\bar{k}_{0}\right)-\mu \bar{k}_{0}\right] \cdot 1,
$$

(B) a utility gain ensuing from consuming the additional net product (5) in all future periods $t$ $=1,2,3, \ldots$ In each period this utility gain is

$$
u^{\prime}\left[f\left(\bar{k}_{0}\right)-\mu \bar{k}_{0}\right] \cdot\left[f^{\prime}\left(\bar{k}_{0}\right)-\mu\right]
$$

The flow of utility gains (7) arising from the additional consumption in all future periods $t=$ $1,2,3, \ldots$ discounted at $t=0$ is

$$
\frac{u^{\prime}\left[f\left(\bar{k}_{0}\right)-\mu \bar{k}_{0}\right] \cdot\left[f^{\prime}\left(\bar{k}_{0}\right)-\mu\right]}{1+\theta}+\frac{u^{\prime}\left[f\left(\bar{k}_{0}\right)-\mu \bar{k}_{0}\right]\left[f^{\prime}\left(\bar{k}_{0}\right)-\mu\right]}{(1+\theta)^{2}}+\frac{u^{\prime}\left[f\left(\bar{k}_{0}\right)-\mu \bar{k}_{0}\right] \cdot\left[f^{\prime}\left(\bar{k}_{0}\right)-\mu\right]}{(1+\theta)^{3}}+\ldots=
$$

\footnotetext{
${ }^{12}$ In what follows, a provisional value assumed by a certain variable is denoted by apex ${ }^{\circ}$ and the definitive value assumed by that variable by apex ${ }^{\bullet}$.

${ }^{13}$ In continuity with the Cass-Koopmans-Ramsey model, the approach here proposed considers utility as a cardinal magnitude (see the crucial role played here by the marginal utility $u^{\prime}(c)$ ). It should be possible to reshape the whole procedure here proposed in ordinal terms, but this will be object of a future work.
} 


$$
=u^{\prime}\left[f\left(\bar{k}_{0}\right)-\mu \bar{k}_{0}\right] \cdot\left[f^{\prime}\left(\bar{k}_{0}\right)-\mu\right] \cdot \sum_{t=1}^{+\infty}\left(\frac{1}{1+\theta}\right)^{t}=\frac{u^{\prime}\left[f\left(\bar{k}_{0}\right)-\mu \bar{k}_{0}\right] \cdot\left[f^{\prime}\left(\bar{k}_{0}\right)-\mu\right]}{\theta}
$$

(notice that all relevant functions in (6), (7) and (8) are evaluated at the levels of capital services per worker and of consumption per worker planned through (Y0-) before reallocation (a)-(b) takes place, that is, $\bar{k}_{0}$ and $\left.f\left(\bar{k}_{0}\right)-\mu \bar{k}_{0}\right)$.

Hence by comparing (A) with (B) we obtain

$$
u^{\prime}\left[f\left(\bar{k}_{0}\right)-\mu \bar{k}_{0}\right]<\frac{u^{\prime}\left[f\left(\bar{k}_{0}\right)-\mu \bar{k}_{0}\right] \cdot\left[f^{\prime}\left(\bar{k}_{0}\right)-\mu\right]}{\theta}
$$

as $\left[f^{\prime}\left(\bar{k}_{0}\right)-\mu\right] / \theta>1$, thanks to $(4)$.

Inequality (9) signals that the consumer can improve his utility by saving this unit, and probably other units of the good. In order to determine how many units it is convenient to save, the consumer must solve the following problem. Let

$$
\begin{aligned}
& c_{0}=f\left(\bar{k}_{0}\right)-\mu \bar{k}_{0}-\left(k_{1}-\bar{k}_{0}\right) \text { be the reduced consumption in period } t=0, \\
& c_{1}=f\left(k_{1}\right)-\mu k_{1} \text { be the increased consumption in period } t=1
\end{aligned}
$$

and, therefore,

$$
c_{t}=f\left(k_{1}\right)-\mu k_{1}, t \geq 2, \text { be the increased consumption in periods } t=2,3,4, \ldots,
$$

where $k_{1}$ is the solution of:

$$
\begin{aligned}
\max _{k_{1}} W_{0} & =u\left[f\left(\bar{k}_{0}\right)-\mu \bar{k}_{0}-\left(k_{1}-\bar{k}_{0}\right)\right]+\frac{1}{1+\theta} u\left[f\left(k_{1}\right)-\mu k_{1}\right]+\left(\frac{1}{1+\theta}\right)^{2} u\left[f\left(k_{1}\right)-\mu k_{1}\right]+ \\
& +\left(\frac{1}{1+\theta}\right)^{3} u\left[f\left(k_{1}\right)-\mu k_{1}\right]+\cdots=u\left[f\left(\bar{k}_{0}\right)-\mu \bar{k}_{0}-\left(k_{1}-\bar{k}_{0}\right)\right]+u\left[f\left(k_{1}\right)-\mu k_{1}\right] \cdot \sum_{t=1}^{+\infty}\left(\frac{1}{1+\theta}\right)^{t}= \\
& =u\left[f\left(\bar{k}_{0}\right)-\mu \bar{k}_{0}-\left(k_{1}-\bar{k}_{0}\right)\right]+\frac{u\left[f\left(k_{1}\right)-\mu k_{1}\right]}{\theta} .
\end{aligned}
$$

The first order condition for a maximum is

$$
\frac{\mathrm{d} W_{0}}{\mathrm{~d} k_{1}}=0: \quad u^{\prime}\left[f\left(\bar{k}_{0}\right)-\mu \bar{k}_{0}-\left(k_{1}-\bar{k}_{0}\right)\right] \cdot(-1)+\frac{u^{\prime}\left[f\left(k_{1}\right)-\mu k_{1}\right] \cdot\left[f^{\prime}\left(k_{1}\right)-\mu\right]}{\theta}=0 .
$$

By re-arranging (11) we obtain

$$
u^{\prime}\left[f\left(\bar{k}_{0}\right)-\mu \bar{k}_{0}-\left(k_{1}-\bar{k}_{0}\right)\right]=\frac{u^{\prime}\left[f\left(k_{1}\right)-\mu k_{1}\right]}{\theta}\left[f^{\prime}\left(k_{1}\right)-\mu\right] .
$$

(W0) is an equation in $k_{1}$. It is a particular case of equation (Wt) (see below, Section 5) where parameter $k_{t}$ is fixed at $k_{t}=\bar{k}_{0}$. Hence, by applying Lemma 1 below, (W0) has a unique solution, $k_{1}^{\bullet}$, such that 


$$
\bar{k}_{0}<k_{1}^{\bullet}<k^{*}
$$

The second order condition,

$\frac{\mathrm{d}^{2} W_{0}}{\mathrm{~d} k_{1}^{2}}<0$, i.e. $\quad u^{\prime \prime}(\cdot)+\frac{1}{\theta}\left\{u^{\prime \prime}(\cdot) \cdot\left[f^{\prime}\left(k_{1}\right)-\mu\right]^{2}+u^{\prime}(\cdot) \cdot f^{\prime \prime}\left(k_{1}\right)\right\}<0$

is satisfied at $k_{1}=k_{1}^{\circ}$ as $u^{\prime}>0, u^{\prime \prime}<0$ and $f^{\prime \prime}<0$.

At this point, let's suppose that the revised consumption flow

$$
c_{0}^{\bullet}=f\left(\bar{k}_{0}\right)-\mu \bar{k}_{0}-\left(k_{1}^{\cdot}-\bar{k}_{0}\right)<f\left(\bar{k}_{0}\right)-\mu \bar{k}_{0}
$$

is actually consumed entirely during period 0 .

Consider now what happens at date $t=1$. The consumer could consume what he had planned in the previous period

$$
f\left(k_{1}^{\bullet}\right)-\mu k_{1}^{\bullet}, t=1,2,3, \ldots
$$

In this situation, consider the intertemporal re-allocation:

(c) in period $t=1$ save and invest 1 unit of the good;

(d) the unit saved in period $t=1$ results in

$$
f^{\prime}\left(k_{1}^{*}\right)-\mu
$$

units of additional net product in all future periods $t=2,3,4, \ldots$

The effects of (c) and (d) on consumer welfare are:

(C) a loss of utility for saving 1 unit in period $t=1$ given by

$$
u^{\prime}\left[f\left(k_{1}^{*}\right)-\mu k_{1}^{*}\right] \cdot 1
$$

(D) a utility gain ensuing from consuming the additional net product (13) in all future periods $t=2,3,4, \ldots$ In each period this utility gain is

$$
u^{\prime}\left[f\left(k_{1}^{*}\right)-\mu k_{1}^{*}\right] \cdot\left[f^{\prime}\left(k_{1}^{*}\right)-\mu\right] .
$$

The flow of utility gains (15) arising from this additional consumption in all future periods $t=$ $2,3,4, \ldots$ discounted at $t=1$ is

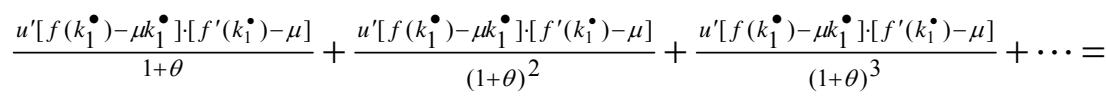

$$
\begin{aligned}
& =u^{\prime}\left[f\left(k_{1}^{*}\right)-\mu k_{1}^{*}\right] \cdot\left[f^{\prime}\left(k_{1}^{*}\right)-\mu\right] \cdot \sum_{t=1}^{+\infty}\left(\frac{1}{1+\theta}\right)^{t}=\frac{u^{\prime}\left[f\left(k_{1}^{*}\right)-\mu k_{1}^{*}\right] \cdot\left[f^{\prime}\left(k_{1}^{*}\right)-\mu\right]}{\theta}
\end{aligned}
$$


(again, all relevant functions in (14), (15) and (16) are evaluated at the levels of capital services per worker and of consumption per worker planned through (Y1-) before reallocation (c)-(d) takes place).

Hence by comparing (C) with (D) we obtain

$$
u^{\prime}\left[f\left(k_{1}^{\bullet}\right)-\mu k_{1}^{\bullet}\right]<\frac{u^{\prime}\left[f\left(k_{1}^{\bullet}\right)-\mu k_{1}^{\bullet}\right] \cdot\left[f^{\prime}\left(k_{1}^{\bullet}\right)-\mu\right]}{\theta}
$$

as $\left[f^{\prime}\left(k_{1}^{\bullet}\right)-\mu\right] / \theta>1$, thanks to (12).

Inequality (17) signals that the consumer can improve his utility by saving this unit, and probably other units of the good. In order to determine how many units it is convenient to save, the consumer must solve the following problem. Let

$$
\begin{aligned}
& c_{1}=f\left(k_{1}^{\bullet}\right)-\mu k_{1}^{\bullet}-\left(k_{2}-k_{1}^{\bullet}\right) \text { be the reduced consumption in period } t=1, \\
& c_{2}=f\left(k_{2}\right)-\mu k_{2} \text { be the increased consumption in period } t=2
\end{aligned}
$$

and, therefore,

$$
c_{t}=f\left(k_{2}\right)-\mu k_{2}, t \geq 3, \text { be the increased consumption in periods } t=3,4,5, \ldots,
$$

where $k_{2}$ is the solution of:

$$
\begin{aligned}
\max _{k_{2}} W_{1} & =u\left[f\left(k_{1}^{\bullet}\right)-\mu k_{1}^{\bullet}-\left(k_{2}-k_{1}^{\bullet}\right)\right]+\frac{1}{1+\theta} u\left[f\left(k_{2}\right)-\mu k_{2}\right]+\left(\frac{1}{1+\theta}\right)^{2} u\left[f\left(k_{2}\right)-\mu k_{2}\right]+ \\
& +\left(\frac{1}{1+\theta}\right)^{3} u\left[f\left(k_{2}\right)-\mu k_{2}\right]+\cdots=u\left[f\left(k_{1}^{\bullet}\right)-\mu k_{1}^{\bullet}-\left(k_{2}-k_{1}^{\bullet}\right)\right]+u\left[f\left(k_{2}\right)-\mu k_{2}\right] \cdot \sum_{t=1}^{+\infty}\left(\frac{1}{1+\theta}\right)^{t}= \\
& =u\left[f\left(k_{1}^{\bullet}\right)-\mu k_{1}^{\bullet}-\left(k_{2}-k_{1}^{\bullet}\right)\right]+\frac{u\left[f\left(k_{2}\right)-\mu k_{2}\right]}{\theta} .
\end{aligned}
$$

The first order condition for a maximum is

$$
\frac{\mathrm{d} W_{1}}{\mathrm{~d} k_{2}}=0: \quad u^{\prime}\left[f\left(k_{1}^{\bullet}\right)-\mu k_{1}^{\bullet}-\left(k_{2}-k_{1}^{\bullet}\right)\right] \cdot(-1)+\frac{u^{\prime}\left[f\left(k_{2}\right)-\mu k_{2}\right]}{\theta} \cdot\left[f^{\prime}\left(k_{2}\right)-\mu\right]=0 .
$$

Re-arranging (19) we obtain:

$$
u^{\prime}\left[f\left(k_{1}^{\bullet}\right)-\mu k_{1}^{\bullet}-\left(k_{2}-k_{1}^{\bullet}\right)\right]=\frac{u^{\prime}\left[f\left(k_{2}\right)-\mu k_{2}\right]}{\theta}\left[f^{\prime}\left(k_{2}\right)-\mu\right] .
$$

(W1) is an equation in $k_{2}$. It is a particular case of equation (Wt) (see below, Section 5) where parameter $k_{t}$ is fixed at $k_{t}=k_{1}^{\bullet}$. Hence, by applying Lemma 1 below, (W1) has a unique solution, $k_{2}^{\bullet}$, such that

$$
k_{1}^{\bullet}<k_{2}^{\bullet}<k^{*}
$$


(for the same reasons noted before, the second order condition is satisfied). At this point, let's suppose that the revised consumption flow

$$
c_{1}^{\bullet}=f\left(k_{1}^{\bullet}\right)-\mu k_{1}^{\bullet}-\left(k_{2}^{\bullet}-k_{1}^{\bullet}\right)<f\left(k_{1}^{\bullet}\right)-\mu k_{1}^{\bullet}
$$

is actually consumed entirely during period 1 .

Remark. As soon as $c_{1}$ is revised from $f\left(k_{1}^{\bullet}\right)-\mu k_{1}^{\bullet}$ to $c_{1}^{\bullet}$, the optimal level of consumption planned for period $t=0, c_{0}^{\bullet}$, is no longer optimal (in fact, the latter was determined by assuming that $c_{1}$ was settled at $f\left(k_{1}^{\bullet}\right)-\mu k_{1}^{\bullet}$, not at $\left.c_{1}^{\bullet}\right)$. However, assuming that $c_{0}^{\bullet}$ is entirely consumed during period $t=0$ prevents us from any possible further re-adjustment of $c_{0}$. We will return later to this point (see Section 6).

Let us now consider what happens at a generic date $t$. The stock $k_{t}$ is given; suppose

$$
k_{t}<k^{*} \text {. }
$$

The consumer can consume in each period

$$
c_{t+\tau}=f\left(k_{t}\right)-\mu k_{t} \quad \tau=0,1,2,3, \ldots
$$

In this situation, consider the intertemporal re-allocation:

(e) in period $t$ save and invest 1 unit of the good;

(f) the unit saved in period $t$ results in

$$
f^{\prime}\left(k_{t}\right)-\mu
$$

units of additional net product in all future periods $t+1, t+2, t+3 \ldots$.

The effects of (e) and (f) on consumer welfare are

(E) a loss of utility for saving 1 unit in period $t$ given by

$$
u^{\prime}\left[f\left(k_{t}\right)-\mu k_{t}\right] \cdot 1
$$

(F) a utility gain ensuing from consuming the additional net product (21) in all future periods $t+1, t+2, t+3, \ldots$ In each period this utility gain is

$$
u^{\prime}\left[f\left(k_{t}\right)-\mu k_{t}\right] \cdot\left[f^{\prime}\left(k_{t}\right)-\mu\right] .
$$

The flow of utility gains (23) arising from this additional consumption in all future periods $t+$ $1, t+2, t+3, \ldots$ discounted at $t$ is

$$
\begin{array}{r}
\frac{u^{\prime}\left[f\left(k_{t}^{\bullet}\right)-\mu k_{t}^{\bullet}\right] \cdot\left[f^{\prime}\left(k_{t}^{*}\right)-\mu\right]}{1+\theta}+\frac{u^{\prime}\left[f\left(k_{t}^{\bullet}\right)-\mu k_{t}^{\bullet}\right] \cdot\left[f^{\prime}\left(k_{i 1}^{*}\right)-\mu\right]}{(1+\theta)^{2}}+\frac{u^{\prime}\left[f\left(k_{t 1}^{\bullet}\right)-\mu k_{t}^{\bullet}\right] \cdot\left[f^{\prime}\left(k_{t}^{*}\right)-\mu\right]}{(1+\theta)^{3}}+\cdots= \\
=u^{\prime}\left[f\left(k_{t}\right)-\mu k_{t}\right] \cdot\left[f^{\prime}\left(k_{t}\right)-\mu\right] \cdot \sum_{\tau=1}^{+\infty}\left(\frac{1}{1+\theta}\right)^{\tau}=\frac{u^{\prime}\left[f\left(k_{t}\right)-\mu k_{t}\right] \cdot\left[f^{\prime}\left(k_{t}\right)-\mu\right]}{\theta}
\end{array}
$$


(again, all relevant functions in (22), (23) and (24) are evaluated at the levels of capital services per worker and of consumption per worker planned through (Yt-) before reallocation (e)-(f) takes place).

Hence by comparing (E) with (F) we obtain

$$
u^{\prime}\left[f\left(k_{t}\right)-\mu k_{t}\right]<\frac{u^{\prime}\left[f\left(k_{t}\right)-\mu k_{t}\right] \cdot\left[f^{\prime}\left(k_{t}\right)-\mu\right]}{\theta}
$$

as $\left[f^{\prime}\left(k_{t}\right)-\mu\right] / \theta>1$, thanks to $(20)$.

Inequality (25) signals that the consumer can improve his utility by saving this unit, and probably other units of the good. In order to determine how many units it is convenient to save, the consumer must solve the following problem. Let

$$
\begin{aligned}
& c_{t}=f\left(k_{t}\right)-\mu k_{t}-\left(k_{t+1}-k_{t}\right) \text { be the reduced consumption in period } t, \\
& c_{t+1}=f\left(k_{t+1}\right)-\mu k_{t+1} \text { be the increased consumption in period } t+1
\end{aligned}
$$

and, therefore,

$$
c_{t+\tau}=f\left(k_{t+1}\right)-\mu k_{t+1}, \tau \geq 2 \text { be the increased consumption in periods } t+2, t+3, t+4, \ldots,
$$

where $k_{t+1}$ is the solution of:

$$
\begin{aligned}
\max _{k_{t+1}} W_{t} & =u\left[f\left(k_{t}\right)-\mu k_{t}-\left(k_{t+1}-k_{t}\right)\right]+\frac{1}{1+\theta} u\left[f\left(k_{t+1}\right)-\mu k_{t+1}\right]+\left(\frac{1}{1+\theta}\right)^{2} u\left[f\left(k_{t+1}\right)-\mu k_{t+1}\right]+\cdots= \\
& =u\left[f\left(k_{t}\right)-\mu k_{t}-\left(k_{t+1}-k_{t}\right)\right]+u\left[f\left(k_{t+1}\right)-\mu k_{t+1}\right] \cdot \sum_{\tau=1}^{+\infty}\left(\frac{1}{1+\theta}\right)^{\tau}= \\
& =u\left[f\left(k_{t}\right)-\mu k_{t}-\left(k_{t+1}-k_{t}\right)\right]+\frac{u\left[f\left(k_{t+1}\right)-\mu k_{t+1}\right]}{\theta} .
\end{aligned}
$$

The first order condition for a maximum is

$$
\frac{\mathrm{d} W_{t}}{\mathrm{~d} k_{t+1}}=0: \quad u^{\prime}\left[f\left(k_{t}\right)-\mu k_{t}-\left(k_{t+1}-k_{t}\right)\right] \cdot(-1)+\frac{u^{\prime}\left[f\left(k_{t+1}\right)-\mu k_{t+1}\right]}{\theta} \cdot\left[f^{\prime}\left(k_{t+1}\right)-\mu\right]=0
$$

Re-arranging (27) we obtain:

$$
u^{\prime}\left[f\left(k_{t}\right)-\mu k_{t}-\left(k_{t+1}-k_{t}\right)\right]=\frac{u^{\prime}\left[f\left(k_{t+1}\right)-\mu k_{t+1}\right]}{\theta}\left[f^{\prime}\left(k_{t+1}\right)-\mu\right] .
$$

(Wt) is an equation in $k_{t+1} \cdot{ }^{14}$ Hence, by applying Lemma 1 below, it has a unique solution, $k_{t+1}^{\bullet}$, such that

\footnotetext{
${ }^{14}$ Analogously to the case considered in footnote 7 above, if the physical constraint is expressed as in $\left(\mathrm{Ct}^{\prime}\right)$ instead of $(\mathrm{Ct})$, constraints (26) become

$c_{t+1}=f\left(k_{t}\right)-\mu k_{t}-\left(k_{t+1}-k_{t}\right)$ be the reduced consumption in period $t$,

$c_{t+2}=f\left(k_{t+1}\right)-\mu k_{t+1}$ be the increased consumption in period $t+1$
} 


$$
k_{t}<k_{t+1}^{\bullet}<k^{*}
$$

It is straightforward to prove that the second derivative, $\mathrm{d}^{2} W_{t} / \mathrm{d} k_{t+1}^{2}$, evaluated at $k_{t+1}^{\bullet}$, is negative. As before, let's suppose that the revised consumption flow

$$
c_{t}^{\bullet}=f\left(k_{t}\right)-\mu k_{t}-\left(k_{t+1}^{\bullet}-k_{t}\right)<f\left(k_{t}\right)-\mu k_{t}
$$

is actually consumed entirely during period $t$.

\section{Convergence to the steady state}

In this Section the analytical properties of equation $(\mathrm{Wt})$ are studied. The results relevant from an economic point of view will be gathered in the Proposition at the end of this Section. Let

$$
\begin{gathered}
g_{k_{t}}\left(k_{t+1}\right):=u^{\prime}\left[(1-\mu) k_{t}+f\left(k_{t}\right)-k_{t+1}\right], \\
h\left(k_{t+1}\right):=\frac{u^{\prime}\left[f\left(k_{t+1}\right)-\mu k_{t+1}\right]}{\theta}\left[f^{\prime}\left(k_{t+1}\right)-\mu\right] ;
\end{gathered}
$$

$g$ is a function of $k_{t+1}$ parameterized by $k_{t}$.

and

$c_{t+\tau}=f\left(k_{t+1}\right)-\mu k_{t+1}, \tau \geq 3$ be the increased consumption in periods $t+3, t+4, t+5, \ldots$,

but still conditions $(\mathrm{W} t)$ remain unaltered, with the only difference that now the arguments of the marginal utilities at the left-hand and at the right-hand are now $c_{t+1}$ and $c_{t+2}$; consequently conditions $(\mathrm{W} t)$ expressed in terms of $c_{t+\tau}$ take the form

$$
u^{\prime}\left(c_{t+1}\right)=\frac{u^{\prime}\left(c_{t+2}\right) \cdot\left[f^{\prime}\left(k_{t+1}\right)-\mu\right]}{\theta}, \quad t=0,1,2, \ldots
$$




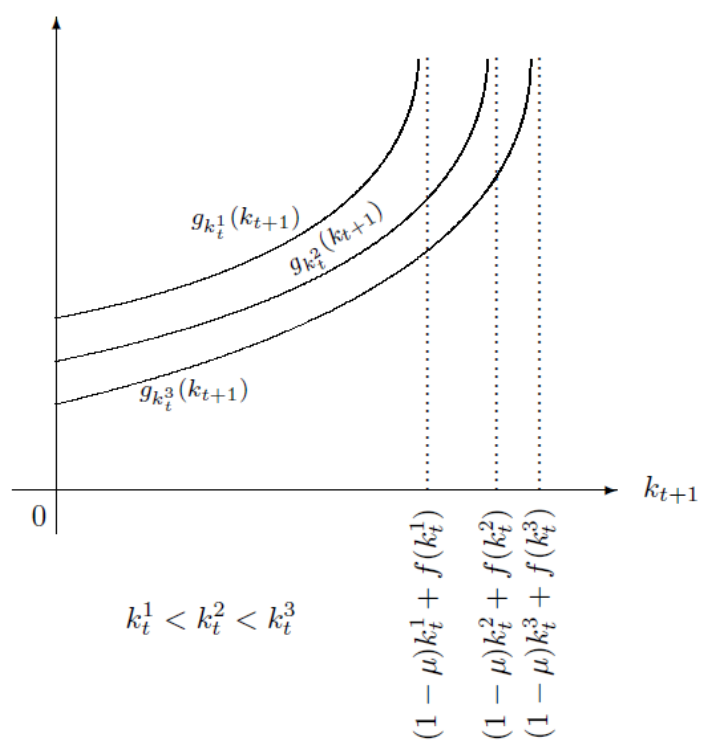

Figure 3. Curves $g_{k_{t}}\left(k_{t+1}\right)$

Properties of $g$. Parameter $k_{t}$ defines a sheaf of curves. Each of these curves is defined, continuous and strictly increasing for $k_{t+1} \in G_{k_{t}}=\left[0,(1-\mu) k_{t}+f\left(k_{t}\right)\right]$ (as $u^{\prime}$ is decreasing). In the first quadrant, each of these curves has a finite and positive interception with the vertical axis, $u^{\prime}\left[(1-\mu) k_{t}+f\left(k_{t}\right)\right]$, and a vertical asymptote given by $k_{t+1}=(1-\mu) k_{t}+f\left(k_{t}\right)$. When parameter $k_{t}$ increases, the interception with the vertical axis decreases, the abscissa of the vertical asymptote increases, and curve $g_{k_{t}}(\cdot)$ shifts downward, that is,

$$
g_{k_{t}}(k)>g_{k_{t+1}}(k) \text { if } k_{t}<k_{t+1} \text {. }
$$

for those $k$ where they are both defined. Hence, curves $g_{k_{t}}(\cdot)$ never intersect themselves; they appear as in Figure 3.

Properties of $h$. Function $h\left(k_{t+1}\right)$ is defined where $f\left(k_{t+1}\right)-\mu k_{t+1}>0$, that is, for $0<k_{t+1}<\tilde{k}$, where $\tilde{k}$ is that level of $k$ defined by (1) which makes the net product equal to zero. 


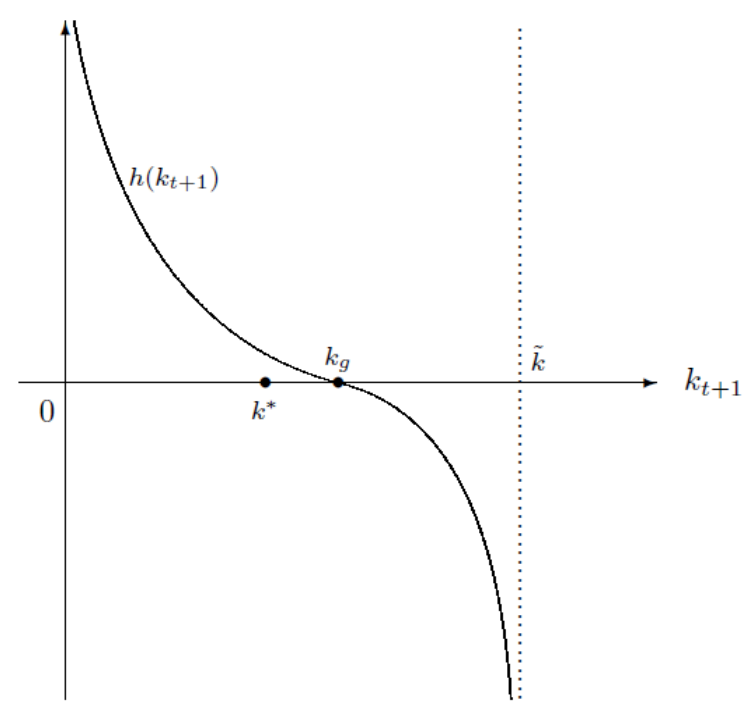

Figure 4. Curve $h\left(k_{t+1}\right)$

Moreover,

$$
\lim _{k_{t+1} \rightarrow 0^{+}} h\left(k_{t+1}\right)=\frac{u^{\prime}\left[f\left(0^{+}\right)-\mu 0^{+}\right]}{\theta}\left[f^{\prime}\left(0^{+}\right)-\mu\right]=\frac{u^{\prime}\left(0^{+}\right)}{\theta}[+\infty-\mu]=(+\infty)(+\infty)=+\infty
$$

$\lim _{k_{t+1} \rightarrow \tilde{k}^{-}} h\left(k_{t+1}\right)=\frac{u^{\prime}\left[f\left(\tilde{k}^{-}\right)-\mu \tilde{k}^{-}\right]}{\theta}\left[f^{\prime}\left(\tilde{k}^{-}\right)-\mu\right]=\frac{u^{\prime}\left(0^{+}\right)}{\theta}\left[f^{\prime}\left(\tilde{k}^{-}\right)-\mu\right]=(+\infty)\left[f^{\prime}\left(\tilde{k}^{-}\right)-\mu\right]=-\infty$

as $f^{\prime}(\tilde{k})-\mu<0$ (see Figure 1$)$. Moreover,

$$
\begin{gathered}
h\left(k_{g}\right)=\frac{u^{\prime}\left[f\left(k_{g}\right)-\mu k_{g}\right]}{\theta}\left[f^{\prime}\left(k_{g}\right)-\mu\right]=\frac{u^{\prime}\left[f\left(k_{g}\right)-\mu k_{g}\right]}{\theta} \cdot 0=0 \\
\frac{\mathrm{d} h}{\mathrm{~d} k_{t+1}}=u^{\prime \prime}\left[f\left(k_{t+1}\right)-\mu k_{t+1}\right] \frac{\left[f^{\prime}\left(k_{t+1}\right)-\mu\right]^{2}}{\theta}+u^{\prime}\left[f\left(k_{t+1}\right)-\mu k_{t+1}\right] \frac{f^{\prime \prime}\left(k_{t+1}\right)}{\theta}<0
\end{gathered}
$$

as $u^{\prime \prime}<0$ and $f^{\prime \prime}<0$ in $0<k_{t+1}<\tilde{k}$. Curve $h\left(k_{t+1}\right)$ appears as in Figure 4.

Lemma 1. Given $k_{t} \in\left(0, k^{*}\right)$ :

1. there exists a unique $k_{t+1}^{\bullet} \in(0, \hat{k})$ which solves (Wt), where $\hat{k}=\min \left[(1-\mu) k_{t}+f\left(k_{t}\right)\right.$, $k_{g}$ ], that is, there exists a unique $k_{t+1}^{\bullet}$ which solves (Wt) on the interval where both $g_{k_{t}}\left(k_{t+1}\right)$ and $h\left(k_{t+1}\right)$ are defined and positive;

2. $k_{t+1}^{\bullet}>k_{t}$; 
3. $k_{t+1}^{\bullet}<k^{*}$.

Proof.

1. Consider equation $g_{k_{t}}\left(k_{t+1}\right)=h\left(k_{t+1}\right)$ on the restricted domain $k_{t+1} \in[0, \hat{k}]$. For $k_{t+1} \rightarrow 0^{+}$we have $g_{k_{t}}\left(0^{+}\right)=g_{k_{t}}(0)=u^{\prime}\left[(1-\mu) k_{t}+f\left(k_{t}\right)\right]$; hence

$$
0<g_{k_{t}}\left(0^{+}\right)<+\infty
$$

by (29) we have

$$
h\left(0^{+}\right)=+\infty .
$$

Hence, by (31) and (32) it follows that

$$
g_{k_{t}}\left(0^{+}\right)<h\left(0^{+}\right)
$$

Since $k_{t+1}=(1-\mu) k_{t}+f\left(k_{t}\right)$ is the vertical asymptote of $g_{k_{t}}\left(k_{t+1}\right)$, we have

$$
g_{k_{t}}\left\{\left[(1-\mu) k_{t}+f\left(k_{t}\right)\right]^{-}\right\}=+\infty \text {. }
$$

In order to compare $g_{k_{t}}$ and $h$ at the other estreme of the domain, $\hat{k}$, three cases must be distinguished:

(a) If

$$
(1-\mu) k_{t}+f\left(k_{t}\right)<k_{g}
$$

then $\hat{k}=(1-\mu) k_{t}+f\left(k_{t}\right)$ and curves $g_{k_{t}}\left(k_{t+1}\right)$ and $h\left(k_{t+1}\right)$ appear as in Figure 5 .

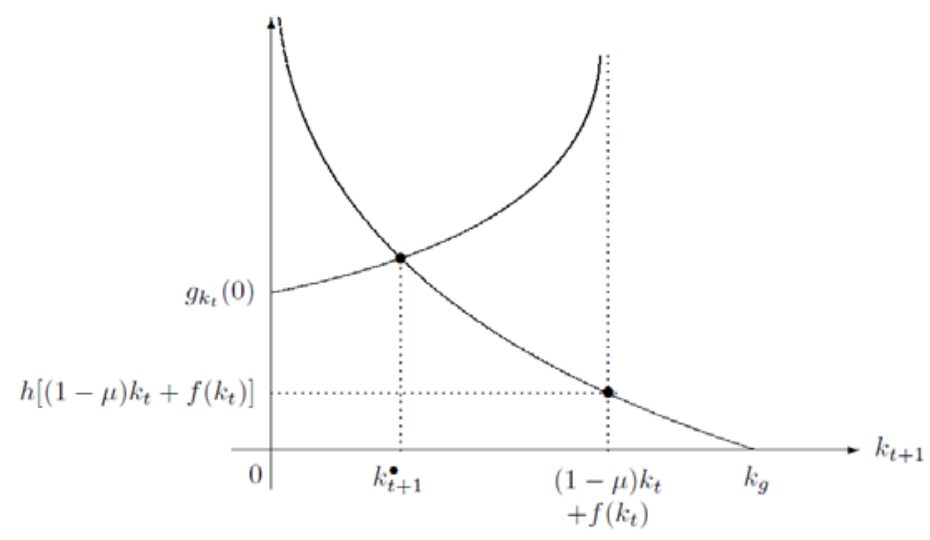

Figure 5. Case 1(a): $(1-\mu) k_{t}+f\left(k_{t}\right)<k_{g}$ 
As $k_{t}>0$ and from (35) we have that $h\left(k_{t+1}\right)$ is finite and positive at $k_{t+1}=(1-\mu) k_{t}+f\left(k_{t}\right)$, that is,

$$
0<h\left[(1-\mu) k_{t}+f\left(k_{t}\right)\right]<\infty .
$$

By (34) and (36) it follows that

$$
g_{k_{t}}\left\{\left[(1-\mu) k_{t}+f\left(k_{t}\right)\right]^{-}\right\}>h\left[(1-\mu) k_{t}+f\left(k_{t}\right)\right] .
$$

By continuity and thanks to (33) and (37), we conclude that there exists a unique

$$
k_{t+1}^{\bullet} \in\left(0,(1-\mu) k_{t}+f\left(k_{t}\right)\right), \quad \text { that is, } k_{t+1}^{\bullet} \in(0, \hat{k})
$$

which satisfies $(\mathrm{Wt})$ (see Figure 5).

(b) If

$$
k_{g}<(1-\mu) k_{t}+f\left(k_{t}\right)
$$

then $\hat{k}=k_{g}$ and curves $g_{k_{t}}\left(k_{t+1}\right)$ and $h\left(k_{t+1}\right)$ appear as in Figure 6. By (38) we deduce that $g_{k_{t}}\left(k_{t+1}\right)$ is finite and positive at $k_{t+1}=k_{g}$, that is

$$
0<g_{k_{t}}\left(k_{g}\right)<+\infty
$$

On the other hand, by (30) we know that

$$
h\left(k_{g}\right)=0 .
$$

Hence, by (39) and (30') it follows that

$$
g_{k_{t}}\left(k_{g}\right)>h\left(k_{g}\right)
$$

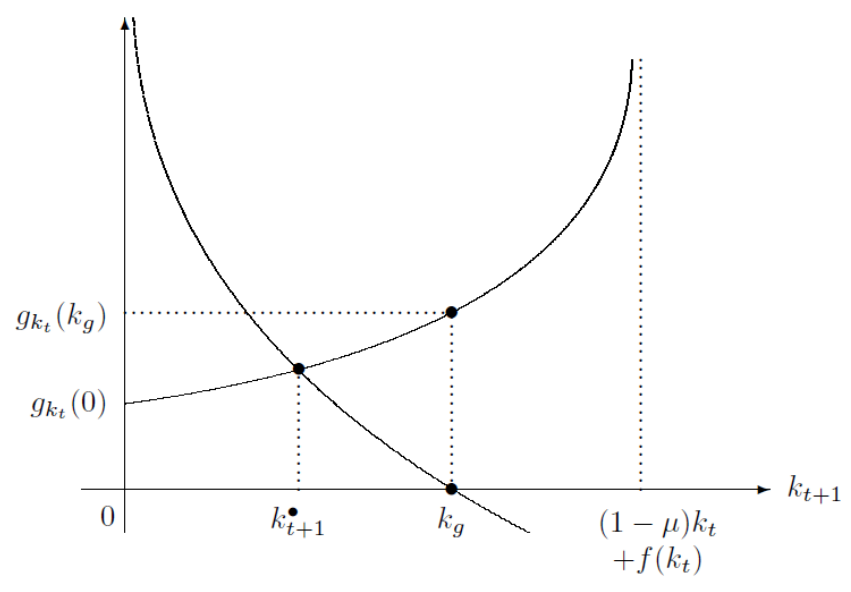

Figure 6. Case 1(b): $k_{g}<(1-\mu) k_{t}+f\left(k_{t}\right)$ 
By continuity and thanks to (33) and (40) we conclude that there exists a unique

$$
k_{t+1}^{\bullet} \in\left(0, k_{g}\right), \text { that is, } k_{t+1}^{\bullet} \in(0, \hat{k})
$$

which satisfies (Wt) (see Figure 6).

(c) If

$$
k_{g}=(1-\mu) k_{t}+f\left(k_{t}\right)
$$

then $\hat{k}=k_{g}=(1-\mu) k_{t}+f\left(k_{t}\right)$ and curves $g_{k_{t}}\left(k_{t+1}\right)$ and $h\left(k_{t+1}\right)$ appear as in Figure 7. In this case

$$
g_{k_{t}}\left(\hat{k}^{-}\right) \equiv g_{k_{t}}\left\{\left[(1-\mu) k_{t}+f\left(k_{t}\right)\right]^{-}\right\}=+\infty
$$

and

$$
h(\hat{k}) \equiv h\left(k_{g}\right)=0
$$

Hence by (41) and (42) it follows that

$$
g_{k_{t}}(\hat{k})>h(\hat{k})
$$

By continuity and thanks to (33) and (43) we conclude that there exists a unique

$$
k_{t+1}^{\bullet} \in(0, \hat{k})
$$

which satisfies (Wt) (see Figure 7).

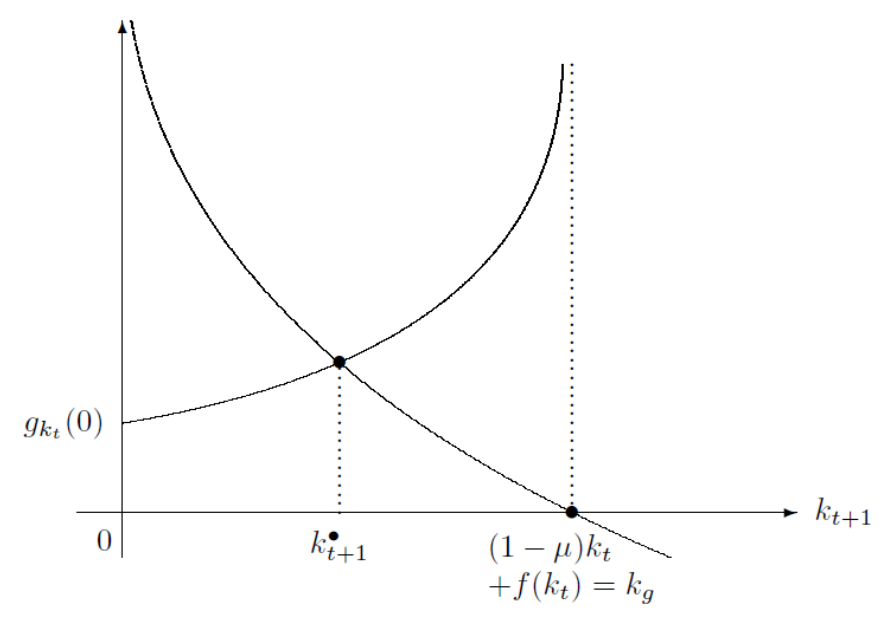

Figure 7. Case 1(c): $k_{g}=(1-\mu) k_{t}+f\left(k_{t}\right)$

2. Evaluate functions $g_{k_{t}}\left(k_{t+1}\right)$ and $h\left(k_{t+1}\right)$ at $k_{t+1}=k_{t}$ : 


$$
\begin{aligned}
& g_{k_{t}}\left(k_{t}\right)=u^{\prime}\left[(1-\mu) k_{t}+f\left(k_{t}\right)-k_{t}\right]=u^{\prime}\left[f\left(k_{t}\right)-\mu k_{t}\right] \\
& h\left(k_{t}\right)=\frac{u^{\prime}\left[f\left(k_{t}\right)-\mu k_{t}\right]}{\theta}\left[f^{\prime}\left(k_{t}\right)-\mu\right]
\end{aligned}
$$

hence $g_{k_{t}}\left(k_{t}\right)<h\left(k_{t}\right)$ as $\left[f^{\prime}\left(k_{t}\right)-\mu\right] / \theta>1$ for $k_{t}<k^{*}$.

Curves $g_{k_{t}}\left(k_{t+1}\right)$ and $h\left(k_{t+1}\right)$ appear as in Figure 8; hence the solution $k_{t+1}^{\bullet}$ of $(\mathrm{W} t)$ must thus lie on the right of $k_{t}$.

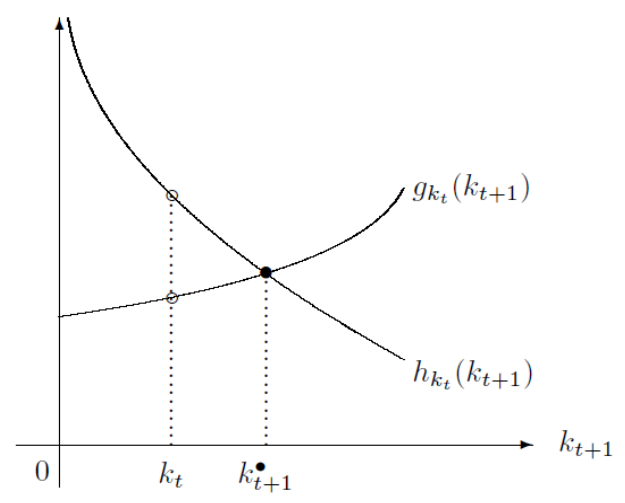

Figure 8. Lemma 1, item 2

3. Draw curves $g_{k_{t}}\left(k_{t+1}\right)$ and $h\left(k_{t+1}\right)$ on the same graph (see Figure 9). Two cases must be distinguished.

(i) If $(1-\mu) k_{t}+f\left(k_{t}\right) \leq k^{*}$, by item 1 of the this Lemma 1, cases (a) or (c), we deduce that $k_{t+1}^{\bullet}<(1-\mu) k_{t}+f\left(k_{t}\right)$; hence $k_{t+1}^{\bullet}<k^{*}$ (see Figure 9(i)).

(ii) If $(1-\mu) k_{t}+f\left(k_{t}\right)>k^{*}$, evaluate $g_{k_{t}}\left(k_{t+1}\right)$ and $h\left(k_{t+1}\right)$ at $k_{t+1}=k^{*}$ :

$$
\begin{aligned}
& g_{k_{t}}\left(k^{*}\right)=u^{\prime}\left[f\left(k_{t}\right)-\mu k_{t}-\left(k^{*}-k_{t}\right)\right] \\
& h\left(k^{*}\right)=\frac{u^{\prime}\left[f\left(k^{*}\right)-\mu k^{*}\right]}{\theta}\left[f^{\prime}\left(k^{*}\right)-\mu\right]=u^{\prime}\left[f\left(k^{*}\right)-\mu k^{*}\right] \text { due to (2). }
\end{aligned}
$$

As $k_{t}<k^{*}$, then $f\left(k_{t}\right)-\mu k_{t}-\left(k^{*}-k_{t}\right)<f\left(k^{*}\right)-\mu k^{*}$; as $u^{\prime}$ is decreasing, then $g_{k_{t}}\left(k^{*}\right)>h\left(k^{*}\right)$. Curves $g_{k_{t}}\left(k_{t+1}\right)$ and $h\left(k_{t+1}\right)$ appear thus as in Figure 9(ii); hence the solution $k_{t+1}^{\bullet}$ of (Wt) must thus lie on the left of $k^{*}$.

This completes the proof. 


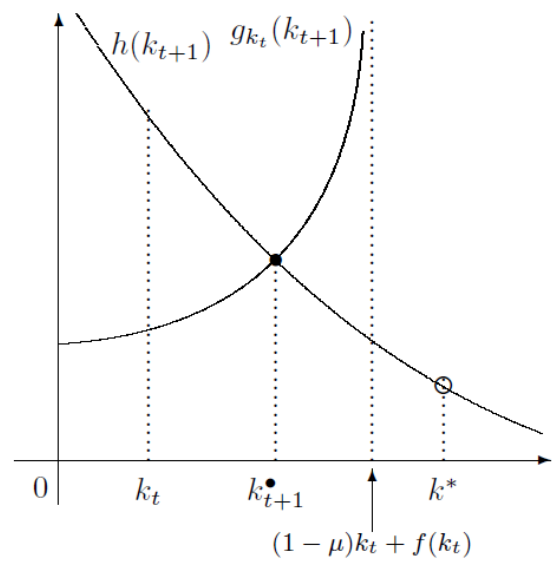

Case (i): $(1-\mu) k_{t}+f\left(k_{t}\right) \leq k^{*}$

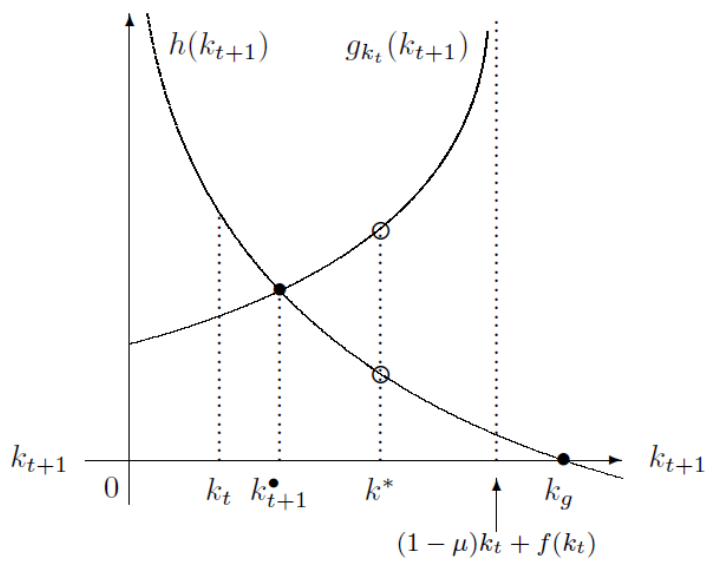

Case(ii): $(1-\mu) k_{t}+f\left(k_{t}\right)>k^{*}$

Figure 9. Lemma 1, item 3

Now, we are going to show that if $k_{0}=k^{*}$, equation (Wt) defines a constant sequence: $k_{t}=k^{*}$, $t=1,2,3, \ldots$.

Lemma 2 If $k_{t}=k^{*}$, there exists a unique $k_{t+1}^{\bullet}=k^{*}$ which solves (Wt).

Proof. Thanks to equation (2) it is straightforward to verify that equation $g_{k^{*}}\left(k_{t+1}\right)=h\left(k_{t+1}\right)$ is satisfied by $k_{t+1}^{\cdot}=k^{*}$. Thus, it is enough to observe that $g_{k^{*}}\left(k_{t+1}\right)$ is a monotonically increasing function of $k_{t+1}$ while $h\left(k_{t+1}\right)$ is a monotonically decreasing function of $k_{t+1}$ to conclude that $k_{t+1}^{\bullet}=k^{*}$ is the unique solution of $g_{k^{*}}\left(k_{t+1}\right)=h\left(k_{t+1}\right)$.

Lemmas 1 and 2 entail that, given $k_{0} \in\left(0, k^{*}\right]$, a sequence $\left\{k_{t}^{\bullet}\right\}_{t=1}^{\infty}$ contained in $\left(0, k^{*}\right]$ is univocally defined by recurrence by equation $(\mathrm{W} t)$.

Lemma 3. $k=k^{*}$ is the unique steady state of sequence $\left\{k_{t}^{\bullet}\right\}_{t=1}^{\infty}$.

Proof. A steady state of $\left\{k_{t}^{\bullet}\right\}_{t=1}^{\infty}$ is a value of $k$ such that $k_{t}=k_{t+1}=k$. Substituting it into (Wt), we obtain:

$$
u^{\prime}[f(k)-\mu k-(k-k)]=\frac{u^{\prime}[f(k)-\mu k]}{\theta}\left[f^{\prime}(k)-\mu\right]
$$

which, after simplification, reduces to, $\left[f^{\prime}(k)-\mu\right] / \theta=1$, whose unique solution is $k=k^{*}$ (see equation (2)). 
Proposition. If $k_{0}=\bar{k}_{0}<k^{*}$, the sequence $\left\{k_{t}^{\bullet}\right\}_{t=1}^{\infty}$ of capital/labour ratios defined by (Wt) converges monotonically to the steady state $k^{*}$ defined by the Ramsey modified golden rule (2).

Proof. By Lemma 1, if $\bar{k}_{0}<k^{*}$ the sequence $\left\{k_{t}^{\bullet}\right\}_{t=1}^{\infty}$ is monotonically increasing (thanks to item 2 ) and upper bounded by $k^{*}$ (thanks to item 3 ). Hence it must converge to some $k^{\prime}$, i.e.,

$$
\lim _{t \rightarrow \infty} k_{t}^{*}=k^{\prime} \text {. }
$$

In order to prove that $k^{\prime}=k^{*}$ observe that, by definition, the elements $k_{t}^{\bullet}$ of the sequence satisfy equations $(\mathrm{W} t)$. Consider the limit for $t \rightarrow \infty$ of $(\mathrm{W} t)$ :

$$
\lim _{t \rightarrow \infty} u^{\prime}\left[f\left(k_{t}^{\bullet}\right)-\mu k_{t}^{\bullet}-\left(k_{t+1}^{\bullet}-k_{t}^{\bullet}\right)\right]=\lim _{t \rightarrow \infty} \frac{u^{\prime}\left[f\left(k_{t+1}^{\bullet}\right)-\mu k_{t+1}^{\bullet}\right]}{\theta}\left[f^{\prime}\left(k_{t+1}^{\bullet}\right)-\mu\right] .
$$

Thanks to the continuity of functions $u^{\prime}, f$ and $f^{\prime}$ we can write

$$
u^{\prime}\left[f\left(\lim _{t \rightarrow \infty} k_{t}^{\bullet}\right)-\mu \lim _{t \rightarrow \infty} k_{t}^{\bullet}-\left(\lim _{t \rightarrow \infty} k_{t+1}^{\bullet}-\lim _{t \rightarrow \infty} k_{t}^{\bullet}\right)\right]=\frac{u^{\prime}\left[f\left(\lim _{t \rightarrow \infty} k_{t+1}^{\bullet}\right)-\mu \lim _{t \rightarrow \infty} k_{t+1}^{\bullet}\right]}{\theta}\left[f^{\prime}\left(\lim _{t \rightarrow \infty} k_{t+1}^{\bullet}\right)-\mu\right]
$$

which, thanks to (44), can be written as

$$
u^{\prime}\left[f\left(k^{\prime}\right)-\mu k^{\prime}-\left(k^{\prime}-k^{\prime}\right)\right]=\frac{u^{\prime}\left[f\left(k^{\prime}\right)-\mu k^{\prime}\right]}{\theta}\left[f^{\prime}\left(k^{\prime}\right)-\mu\right]
$$

after simplification, this equation in $k^{\prime}$ reduces to $\left[f^{\prime}\left(k^{\prime}\right)-\mu\right] / \theta=1$, whose unique solution is $k^{\prime}=k^{*}$ (see equation (2)). This completes the proof.

Figure 10 displays how $\left\{k_{t}^{\bullet}\right\}_{t=1}^{\infty}$ takes shape as sequence of the abscissas of the interceptions of curves $g_{k_{t}}(\cdot)$ with curve $h(\cdot)$. As $\bar{k}_{0}<k_{1}^{\bullet}<k_{2}^{\bullet}<k_{3}^{\bullet}<\cdots<k^{*}$ and thanks to (28), curves $g$ appear as in the diagram. Moreover, it is easy to verify that curve $g_{k^{*}}(k)$ crosses curve $h(k)$ at $k=k^{*}$ : in fact, $g_{k^{*}}\left(k^{*}\right)=u^{\prime}\left[f\left(k^{*}\right)-\mu k^{*}-\left(k^{*}-k^{*}\right)\right]=u^{\prime}\left[f\left(k^{*}\right)-\mu k^{*}\right]$ and $h\left(k^{*}\right)=u^{\prime}$ $\left[f\left(k^{*}\right)-\mu k^{*}\right] \cdot\left[f^{\prime}\left(k^{*}\right)-\mu\right] / \theta=u^{\prime}\left[f\left(k^{*}\right)-\mu k^{*}\right]$. 


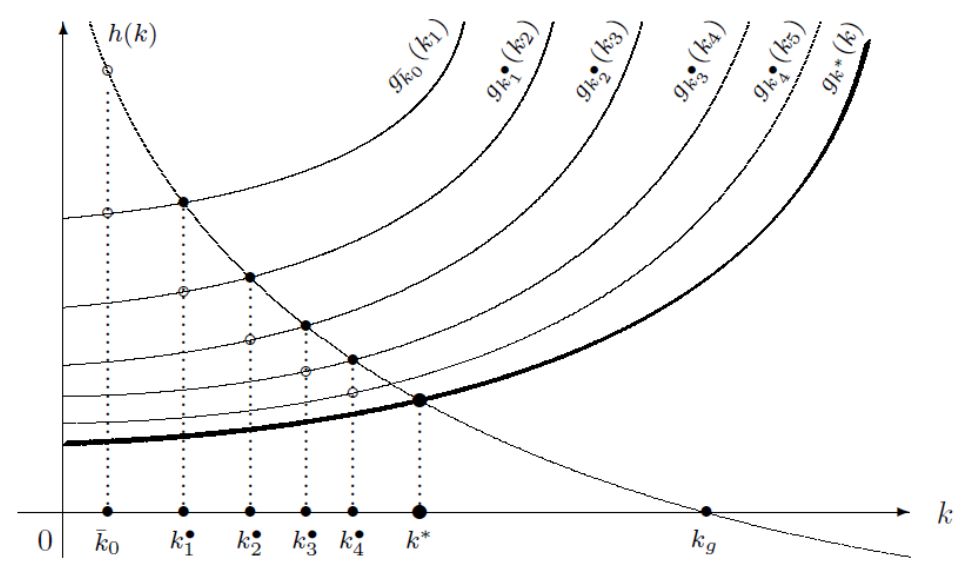

Figure 10. Sequence $\left\{k_{t}^{\bullet}\right\}_{t=1}^{\infty}$

A simplest proof of the convergence result can be given as follows if we limit to a local result: calculate the total differential of (Wt) with respect to $k_{t}$ and $k_{t+1}$ :

$$
\begin{aligned}
u^{\prime \prime}\left[f\left(k_{t}\right)\right. & \left.-\mu k_{t}-k_{t+1}+k_{t}\right]\left\{\left[f^{\prime}\left(k_{t}\right)-\mu+1\right] \mathrm{d} k_{t}-\mathrm{d} k_{t+1}\right\}= \\
& =\frac{1}{\theta}\left\{u^{\prime \prime}\left[f\left(k_{t+1}\right)-\mu k_{t+1}\right]\left[f^{\prime}\left(k_{t+1}\right)-\mu\right]^{2}+u^{\prime}\left[f\left(k_{t+1}\right)-\mu k_{t+1}\right] f^{\prime \prime}\left(k_{t+1}\right)\right\} \mathrm{d} k_{t+1} ;
\end{aligned}
$$

evaluate at the steady state, $k^{*},\left(\right.$ where $\left.f^{\prime}\left(k^{*}\right)-\mu=\theta\right)$ and re-arrange; we obtain

$$
\left.\frac{\mathrm{d} k_{t+1}}{\mathrm{~d} k_{t}}\right|_{*}=\frac{1}{1+\alpha}
$$

where $\alpha=\frac{u^{\prime}\left(\varphi^{*}\right) f^{\prime \prime}\left(k^{*}\right)}{\theta(1+\theta) u^{\prime \prime}\left(\varphi^{*}\right)}$ and $\varphi^{*}=f\left(k^{*}\right)-\mu k^{*}$. As $u^{\prime}>0, u^{\prime \prime}<0$ and $f^{\prime \prime}<0$ then $\alpha>0$ and

$$
0<\left.\frac{\mathrm{d} k_{t+1}}{\mathrm{~d} k_{t}}\right|_{*}<1 .
$$

This proves the local stability of $k^{*}:$ if $\bar{k}_{0}$ is taken sufficiently close to $k^{*}$ then it converges to $k^{*}$ monotonically. The Proposition at page 25 contains a global result.

A remarkable characteristic of the convergence results just seen is that they both have been obtained without assuming any transversality condition, i.e. without the need to anticipate the solution of infinitely many optimization problems. No perfect foresight is thus needed here. For any given level of the capital/labour ratio, $k_{t}$, the consumer chooses $k_{t+1}$ just by comparing the marginal utility of consumption in period $t$ with the marginal utility of a constant flow of consumption in all future periods (from $t+1$ to infinity) discounted at $t$. It could be observed 
that the transversality condition has here been replaced with 'terminal' conditions (Yt-) which, if not as unrealistic as the assumption of perfect foresight (implicit in the transversality condition), bind the consumer to a sub-optimal choice. In fact, in each period the consumer chooses his present consumption assuming zero net savings from the subsequent period onwards. This is a myopic behaviour: the consumer will find it convenient to revise his past decision of consuming the whole net product in each period; consequently, all conditions (Yt) will be removed one after another. Hence, 'terminal' conditions (Yt-) will never be satisfied. Nevertheless, the transversality condition is satisfied by our convergent path. In fact, as $k_{t}$ and $c_{t}$ converge to positive and finite magnitudes, $k^{*}$ and $c^{*}$, we have

$$
\lim _{t \rightarrow \infty} k_{t} u^{\prime}\left(c_{t}\right)\left(\frac{1}{1+\theta}\right)^{t}=k^{*} u^{\prime}\left(c^{*}\right) \lim _{t \rightarrow \infty}\left(\frac{1}{1+\theta}\right)^{t}=0 .
$$

But in the present setting, it is just a consequence of the adjustment process. It is not a requirement to identify the equilibrium path ${ }^{15}$.

\section{6. 'Backward' re-adjustments: towards a generalization}

As observed in the Remark on p. 15, as at the beginning of each period the consumer revises his present and future consumption choices taken in the previous period and provides additional savings, the consumption choices adopted in previous periods should be revised in order to make them coherent with the consumption-savings profile that is taking shape as time goes by. We could disregard these further re-adjustments as we assumed that by the end of each period $t$ the consumer consumed the entire flow of consumption determined for that period, i.e., $c_{t}^{\cdot}$, before the beginning of period $t+1$. We could, however, imagine less simplified settings, where the consumer displays a longer foresight in anticipating his future behaviour. As already noted, in the Ramsey model the decisions to be adopted in the various periods are all connected to each other. If we want to avoid assuming that the consumer actually chooses all future optimal consumption levels in order to select the present one, we could imagine that he (provisionally) smoothes his consumption profile over a finite number of periods only. The step subsequent to that considered in the previous pages is to extend the consumer planning horizon from two periods (the present one and the entire future) to three periods, as described in the following optimization problem:

$$
\begin{aligned}
\max W_{0} & =u\left(c_{0}\right)+\frac{u\left(c_{1}\right)}{1+\theta}+\frac{u\left(c_{2}\right)}{(1+\theta)^{2}}+\frac{u\left(c_{3}\right)}{(1+\theta)^{3}}+\cdots \\
\text { s.v. } c_{0} & =f\left(k_{0}\right)-\mu k_{0}-\left(k_{1}-k_{0}\right), \\
c_{1} & =f\left(k_{1}\right)-\mu k_{1}-\left(k_{2}-k_{1}\right), \\
c_{\tau} & =f\left(k_{2}\right)-\mu k_{2}, \quad \tau \geq 2 .
\end{aligned}
$$

\footnotetext{
${ }^{15}$ Curiously enough, all provisional paths resulting from any finite number of steps of our adjustment processand paradoxically even the initial path from which our adjustment process starts, where $c_{t}$ is provisionally set equal to $f\left(\bar{k}_{0}\right)-\mu \bar{k}_{0}$ for any $t=0,1,2, \ldots$-satisfy the transversality condition.
} 
After substituting the constraints into the objective function the problem can be re-expressed in terms of variables $k_{1}$ and $k_{2}$ only:

$$
\begin{aligned}
\max _{k_{1}, k_{2}} W_{0} & =u\left[f\left(\bar{k}_{0}\right)-\mu \bar{k}_{0}-\left(k_{1}-\bar{k}_{0}\right)\right]+\frac{u\left[f\left(k_{1}\right)-\mu k_{1}-\left(k_{2}-k_{1}\right)\right]}{1+\theta}+ \\
& +\frac{u\left[f\left(k_{2}\right)-\mu k_{2}\right]}{(1+\theta)^{2}}+\frac{u\left[f\left(k_{2}\right)-\mu k_{2}\right]}{(1+\theta)^{3}} \cdots= \\
& =u\left[f\left(\bar{k}_{0}\right)-\mu \bar{k}_{0}-\left(k_{1}-\bar{k}_{0}\right)\right]+\frac{u\left[f\left(k_{1}\right)-\mu k_{1}-\left(k_{2}-k_{1}\right)\right]}{1+\theta}+\frac{u\left[f\left(k_{2}\right)-\mu k_{2}\right]}{\theta(1+\theta)} .
\end{aligned}
$$

In the case considered in the previous sections, once given $k_{0}$, then $k_{1}$ was chosen under the assumption that the ensuing net product, $f\left(k_{1}\right)-\mu k_{1}$, was entirely consumed in each period from the subsequent period onwards.

In the present case, given $k_{0}$, variables $k_{1}$ and $k_{2}$ are chosen under the assumptions that net product $f\left(k_{1}\right)-\mu k_{1}$ is partially consumed and partially saved in period 1 and that this saving is chosen under the assumption that the entire net product $f\left(k_{2}\right)-\mu k_{2}$ will be consumed in each period from period 2 onwards.

The first order conditions of problem (45) $\partial W_{0} / \partial k_{1}=\partial W_{0} / \partial k_{2}=0$, entail:

$$
\begin{gathered}
u^{\prime}\left[f\left(\bar{k}_{0}\right)-\mu \bar{k}_{0}-\left(k_{1}-\bar{k}_{0}\right)\right]=u^{\prime}\left[f\left(k_{1}\right)-\mu k_{1}-\left(k_{2}-k_{1}\right)\right] \frac{f^{\prime}\left(k_{1}\right)-\mu+1}{1+\theta} \\
u^{\prime}\left[f\left(k_{1}\right)-\mu k_{1}-\left(k_{2}-k_{1}\right)\right]=u^{\prime}\left[f\left(k_{2}\right)-\mu k_{2}\right] \frac{f^{\prime}\left(k_{2}\right)-\mu}{\theta} .
\end{gathered}
$$

At $t=2$ the consumer perceives that $c_{\tau}=f\left(k_{2}\right)-\mu k_{2}, \tau \geq 2$ is not optimal. He revises his constant consumption profile into

$$
\begin{gathered}
c_{2}=f\left(k_{2}\right)-\mu k_{2}-\left(k_{3}-k_{2}\right), \\
c_{3}=f\left(k_{3}\right)-\mu k_{3}-\left(k_{4}-k_{3}\right), \\
c_{\tau}=f\left(k_{4}\right)-\mu k_{4}, \quad \tau \geq 4 .
\end{gathered}
$$

where $k_{3}$ and $k_{4}$ are the solution of

$$
\max W_{2}=u\left(c_{2}\right)+\frac{u\left(c_{3}\right)}{1+\theta}+\frac{u\left(c_{4}\right)}{(1+\theta)^{2}}+\frac{u\left(c_{5}\right)}{(1+\theta)^{3}}+\cdots
$$

with $c_{2}, c_{3}$ and $c_{\tau}, \tau \geq 4$, given by (47a), (47b) and (47c) respectively.

The solution of (48) gives rise to another pair of equations analogous to (46) but displaced by two periods. problem,

In general, the dynamics of $k_{t}$ is obtained by solving the following maximization 


$$
\begin{aligned}
\max _{k_{t+1}, k_{t+2}} & W_{t}=u\left[f\left(k_{t}\right)-\mu k_{t}-\left(k_{t+1}-k_{t}\right)\right]+\frac{u\left[f\left(k_{t+1}\right)-\mu k_{t+1}-\left(k_{t+2}-k_{t+1}\right)\right]}{1+\theta}+ \\
& +\frac{u\left[f\left(k_{t+2}\right)-\mu k_{t+2}\right]}{(1+\theta)^{2}}+\frac{u\left[f\left(k_{t+2}\right)-\mu k_{t+2}\right]}{(1+\theta)^{3}}+\cdots= \\
& =u\left[f\left(k_{t}\right)-\mu k_{t}-\left(k_{t+1}-k_{t}\right)\right]+\frac{u\left[f\left(k_{t+1}\right)-\mu k_{t+1}-\left(k_{t+2}-k_{t+1}\right)\right]}{1+\theta}+\frac{u\left[f\left(k_{t+2}\right)-\mu k_{t+2}\right]}{\theta(1+\theta)},
\end{aligned}
$$

whose first order conditions, $\partial W_{t} / \partial k_{1}=\partial W_{t} / \partial k_{2}=0$, entail:

$$
\begin{gathered}
u^{\prime}\left[f\left(k_{t}\right)-\mu k_{t}-\left(k_{t+1}-k_{t}\right)\right]=u^{\prime}\left[f\left(k_{t+1}\right)-\mu k_{t+1}-\left(k_{t+2}-k_{t+1}\right)\right] \frac{f^{\prime}\left(k_{t+1}\right)-\mu+1}{1+\theta}, \\
u^{\prime}\left[f\left(k_{t+1}\right)-\mu k_{t+1}-\left(k_{t+2}-k_{t+1}\right)\right]=u^{\prime}\left[f\left(k_{t+2}\right)-\mu k_{t+2}\right] \frac{f^{\prime}\left(k_{t+2}\right)-\mu}{\theta}
\end{gathered}
$$

Equations (49) implicitly describe a second degree difference system. A detailed study of its analytical properties goes beyond the purpose of the present work.

A simple result is at hand: substituting $k_{t}=k_{t+1}=k_{t+2}=k$ in (49) both equations reduce to

$$
f^{\prime}(k)=\mu+\theta,
$$

whose unique solution is $k=k^{*}$. Hence $k^{*}$ is the unique steady state equilibrium of (49).

\section{Concluding remarks}

The present work has aimed to challenge i) the idea that the instability phenomena of the Cass-Koopmans model (capital zeroing or capital over-accumulation) are strictly connected to a myopic foresight by the consumer in discovering his optimal accumulation path, and, in parallel, that ii) only the introduction of a transversality condition, that is, a sort of perfect foresight condition, is necessary to ensure the convergence of the system to the steady state equilibrium.

Given the practical impossibility of solving the infinitely many optimization problems entailed in the case of an infinite horizon problem or, similarly, placing the initial consumption exactly on the saddle-path, we have proposed an adjustment process in which savings of each period are chosen optimally by assuming, provisionally, the same conventional level of consumption for all future periods. This conventional level is then revised period by period by the same bounded rational procedure. The ensuing adjustment process turns out to be monotonically convergent to the steady state equilibrium. By accepting a 'smaller amount of rationality' for the consumer, the device to approach step by step the optimal path instead of 'jumping' immediately on it has made it possible to select a consumption level for each period without the need to immediately solve the entire set of allocation problems between any of the infinitely many pairs of future periods. The obtained path is optimal within the set of constraints assumed on the consumer's ability to optimize over the future; it is sub-optimal if regarded from a longer horizon. More refined adjustment 
processes, involving more than two periods in each step, should probably be less sub-optimal. Nevertheless, even the simple process here presented leads the consumer to converge to the steady state equilibrium without the necessity to impose a transversality condition, i.e. without assuming perfect foresight or rational expectations.

In conclusion, diverging phenomena like those emerging in the Cass-Koopmans version of the Ramsey model appeared not to be inherent to the main problem analysed (the choice of the optimal consumption-savings path), nor directly connected to myopic optimization. They arise from the presumption that the consumer must select all optimal future consumption levels in order to optimally select the present one.

A generalization of the results here obtained to the case with more than one capital good still needs to be done; however, I suspect that the roots of diverging forces operating in infinite horizon models with more than one good are of the same nature as of those found in a one-commodity model. If this is the case, they should be easily handled without the need of assuming long run perfect foresight optimizing consumers. In other terms, it does not seem imputable to consumers' structural inability to foresee and optimize over the future the main cause for crises, bubbles, etc. A satisfactory explanation of these phenomena is to be found in other directions, probably outside the Neoclassical dynamic capital theory.

\section{References}

AZARIADIS, C. (1993): Intertemporal Macroeconomics. Blackwell, Cambridge, Massachusetts.

BlAnCHARD, O.J., and S. Fischer (1989): Lectures on Macroeconomics. The MIT press, Cambridge, MA.

BLISS, C. (2010): “The Cambridge Post-Keynesians: An Outsiders Insider View”, History of Political Economy, 42(4), 631-652.

CASS, D. (1965): “Optimum Growth in an Aggregative Model of Capital Accumulation”, The Review of Economic Studies, 32(3), 233-40.

HeLler, W.P. (1975): "Tâtonnement Stability of Infinite Horizon Models with Saddle-Point Instability", Econometrica, 43(1), 65-80.

Hicks, J. (1965), Capital and Growth, Clarendon Press, Oxford.

Koopmans, T.C. (1965): "On the Concept of Optimal Economic Growth", Pontificia Academia Scientiarum Scripta Varia, 28(1), 225-87.

Malinvaud, E. (1965): "Croissances optimales dans une modèle macroeconomique", Pontificia Academia Scientiarum Scripta Varia, 28(1), 301-78.

Mas-Colell A., Whinston M. D. and Green J. R. (1995): Microeconomic Theory, Oxford University Press, Oxford.

Nicola, P. (2000): Mainstream Mathematical Economics in the 20th Century, Springer, Berlin. 
RAMSEY, F.P. (1928): "A Mathematical Theory of Saving", The Economic Journal, XXXVIII(152), 543-59.

Stockey, N., and R. LuCAS (1989): Recursive Methods in Economic Dynamics. Harvard University Press, Cambridge Mass., with the collaboration of Edward C. Prescott. 